\title{
Improved Oxygen Reduction Reaction Activity of Nanostructured CoS2 through Electrochemical Tuning
}

Zhao, Wei-Wei; Bothra, Pallavi; Lu, Zhiyi; Li, Yanbin; Mei, Li-Ping; Liu, Kai; Zhao, Zhenghang; Chen, Guangxu; Back, Seoin; Siahrostami, Samira

Total number of authors:

14

Published in:

Applied Energy Materials

Link to article, DOI:

10.1021/acsaem.9b01527

Publication date:

2019

Document Version

Peer reviewed version

Link back to DTU Orbit

Citation $(A P A)$ :

Zhao, W-W., Bothra, P., Lu, Z., Li, Y., Mei, L-P., Liu, K., Zhao, Z., Chen, G., Back, S., Siahrostami, S., Kulkarni, A., Nørskov, J. K., Bajdich, M., \& Cui, Y. (2019). Improved Oxygen Reduction Reaction Activity of Nanostructured CoS through Electrochemical Tuning. Applied Energy Materials, 2(12), 8605-8614. https://doi.org/10.10Z1/acsaem.9b01527

\section{General rights}

Copyright and moral rights for the publications made accessible in the public portal are retained by the authors and/or other copyright owners and it is a condition of accessing publications that users recognise and abide by the legal requirements associated with these rights.

- Users may download and print one copy of any publication from the public portal for the purpose of private study or research.

- You may not further distribute the material or use it for any profit-making activity or commercial gain

- You may freely distribute the URL identifying the publication in the public portal 


\section{Improved Oxygen Reduction Reaction Activity of Nanostructured CoS2 through Electrochemical Tuning}

Wei-Wei Zhao, Pallavi Bothra, Zhiyi Lu, Yanbin Li, Li-Ping Mei, Kai Liu, Zhenghang Zhao, Guangxu Chen, Seoin Back, Samira Siahrostami, Ambarish Kulkarni, Jens K. Nørskov, Michal Bajdich, and Yi Cui ACS Appl. Energy Mater., Just Accepted Manuscript • DOI: 10.1021/acsaem.9b01527 • Publication Date (Web): 24 Oct 2019

Downloaded from pubs.acs.org on November 4, 2019

\section{Just Accepted}

"Just Accepted" manuscripts have been peer-reviewed and accepted for publication. They are posted online prior to technical editing, formatting for publication and author proofing. The American Chemical Society provides "Just Accepted" as a service to the research community to expedite the dissemination of scientific material as soon as possible after acceptance. "Just Accepted" manuscripts appear in full in PDF format accompanied by an HTML abstract. "Just Accepted" manuscripts have been fully peer reviewed, but should not be considered the official version of record. They are citable by the Digital Object Identifier (DOI®). "Just Accepted" is an optional service offered to authors. Therefore, the "Just Accepted" Web site may not include all articles that will be published in the journal. After a manuscript is technically edited and formatted, it will be removed from the "Just Accepted" Web site and published as an ASAP article. Note that technical editing may introduce minor changes to the manuscript text and/or graphics which could affect content, and all legal disclaimers and ethical guidelines that apply to the journal pertain. ACS cannot be held responsible for errors or consequences arising from the use of information contained in these "Just Accepted" manuscripts. 


\section{Improved Oxygen Reduction Reaction Activity of}

\section{Nanostructured $\mathrm{CoS}_{2}$ through Electrochemical Tuning}

Wei-Wei Zhao ${ }^{1,2,7, *}$, Pallavi Bothra ${ }^{4,7}$, Zhiyi $\mathrm{Lu}^{2,6}$, Yanbin $\mathrm{Li}^{2}$, Li-Ping Mei ${ }^{1}$, Kai Liu ${ }^{2}$, Zhenghang Zhao $^{4}$, Guangxu Chen², Seoin Back ${ }^{4}$, Samira Siahrostami ${ }^{4}$, Ambarish Kulkarni ${ }^{4}$, Jens K. Nørskov ${ }^{3,4}$, Michal Bajdich ${ }^{5 *}$ and Yi Cui ${ }^{2,6, *}$

${ }^{1}$ School of Chemistry and Chemical Engineering, State Key Laboratory of Analytical Chemistry for Life Science, Nanjing University, Nanjing 210023, China.

${ }^{2}$ Department of Material Science and Engineering, Stanford University, Stanford, California 94305, United States.

${ }^{3}$ Department of Physics, Technical University of Denmark, 2800 Kongens Lyngby, Denmark ${ }^{4}$ SUNCAT Center for Interface Science and Catalysis, Chemical Engineering, Stanford University, Stanford, California 94305, United States.

${ }^{5}$ SLAC National Accelerator Laboratory, 2575 Sand Hill Road, Menlo Park, California 94025, United States.

${ }^{6}$ Stanford Institute for Materials and Energy Science, SLAC National Accelerator Laboratory, Menlo Park, California 94025, United States.

${ }^{7}$ Contributed equally to this work

Correspondence and requests for materials should be addressed to W.W.Z and Y.C. (experiment) or M.B. (theory)

*Email: zww@nju.edu.cn

*Email: yicui@stanford.edu

*Email: bajdich@slac.stanford.edu 


\begin{abstract}
Searching for efficient Pt-free oxygen reduction reaction (ORR) electrocatalysts has been actively pursued among the current electrocatalyst research community. The family of transition-metal chalcogenides, especially cobalt disulfide $\left(\mathrm{CoS}_{2}\right)$, has been reported as competitive ORR catalysts. Here, we perform a detailed analysis of the intrinsic activity in terms of onset potentials and selectivity towards hydrogen peroxide of $\mathrm{CoS}_{2}$ in both acid and alkaline medium. Our detailed characterizations of this system via X-ray Powder Diffraction (XRD), X-ray photoelectron spectroscopy (XPS) and calculated bulk and surface thermodynamics and ORR mechanism reveal $\mathrm{pH}$-dependent electrochemical evolution of the $\mathrm{CoS}_{2}$ surfaces. Using XPS results before and after ORR in combination with density functional theory (DFT) calculations for individual surfaces reveals sulfur to oxygen substitution and partial dissolution occurs in acidic media, while thin cobalt-oxide films supported by $\mathrm{CoS}_{2}$ are formed in alkaline media. The comprehensive DFT calculations of the ORR activities on these systems reveal that sulfur is unlikely ORR active site, while undercoordinated Co-metal site in the $\mathrm{CoS}_{2}$ is less active than very active undercoordinated Co-metal site in the Co-oxide film. Using these guiding principles, we then demonstrate that electrochemical lithium ( $\mathrm{Li}$ ) tuning of $\mathrm{CoS}_{2}$ in organic electrolyte increases its ORR performance in both acid and alkaline medium. Detailed characterizations demonstrate that the grain size of $\mathrm{CoS}_{2}$ particle is considerably reduced and has a much richer surface oxygen content after electrochemical Li tuning $\left(\mathrm{LiET}-\mathrm{CoS}_{2}\right)$ as the direct consequence of the Li galvanostatic cycling. The general efficacy of this method toward transition metal chalcogenides (T-M-X) is further demonstrated by enhanced ORR activities of $\mathrm{CoS}$ and $\mathrm{Ni}_{3} \mathrm{~S}_{2}$ in alkaline and neutral medium, respectively. This work opens up an opportunity for probing more advanced T-M-X-based catalysts.
\end{abstract}

Keywords: Oxygen reduction reaction; Electrochemical lithium tuning; $\mathrm{CoS}_{2}$; Theoretical overpotential, Transition metal chalcogenides; Grain boundaries; Pourbaix Diagram 


\section{INTRODUCTION}

An efficient oxygen reduction reaction (ORR) offers the potential for clean energy generation in protonexchange membrane fuel cells (PEMFC), which are currently limited by the sluggish oxygen reduction reaction kinetics at the cathode. ${ }^{1,2}$ Platinum-based materials are widely used as high-performance ORR catalysts, ${ }^{3}$ but their scarcity and high cost have impeded the widespread application and commercialization of fuel cells. ${ }^{4}$ To reduce the cost of the cathode while retaining the performance, substantial recent experimental and computational effort has been devoted to the material screening, design, synthesis and improvement of robust ORR electrocatalysts. In particular, the development of Ptfree electrocatalysts in a wide $\mathrm{pH}$-range is being actively pursued by the electrochemistry community. ${ }^{5}$ For example, single-atom transition-metal-N-C catalysts have been reported as competitive alternatives to precious catalyst. ${ }^{6-8}$ While these catalysts have distinct advantages, each also suffers from its own limitations such as the involvement of non-cheap organic precursors, laborious fabrication procedures and high demand for controlling the local environment of the metal center. Therefore, exploration of the facile and efficient nonprecious ORR catalysts is still highly appealing.

The family of transition-metal chalcogenides (T-M-X, where $\mathrm{M}=\mathrm{Co}, \mathrm{Ni}, \mathrm{Fe}, \mathrm{Mn}, \mathrm{Cu}, \mathrm{Zn}$ etc. and $\mathrm{X}$ $=\mathrm{S}, \mathrm{Se}$, or Te) have been investigated as alternative ORR catalysts. ${ }^{1,4}$ As compared to Pt-based catalysts, these T-M-X have a lower cost and are earth abundant. Previous ORR studies have also led to the general activity trends, where $\mathrm{M}_{\mathrm{x}} \mathrm{S}_{\mathrm{y}}>\mathrm{M}_{\mathrm{x}} \mathrm{Se}_{\mathrm{y}}>\mathrm{M}_{\mathrm{x}} \mathrm{Te}_{\mathrm{y}}$ and also $\mathrm{Co}_{\mathrm{x}} \mathrm{X}_{\mathrm{y}}>\mathrm{Ni}_{\mathrm{x}} \mathrm{X}_{\mathrm{y}}>\mathrm{Fe}_{\mathrm{x}} \mathrm{X}_{\mathrm{y}} \cdot{ }^{9}$ Among all chalcogenides of nonprecious metals, cobalt sulfides have demonstrated the highest ORR activity in acidic medium. ${ }^{10,11}$ Despite the progress, the T-M-X-based ORR catalyst developed so far still generally underperform the Pt-based ones. Achieving high-performance T-M-X-based ORR electrocatalyst with comparable activities and durability to Pt benchmark remains a challenge.

Essentially, the intrinsic ORR activity of T-M-X is closely related to structural evolution of their surfaces under electrochemical conditions. The spontaneous transformation of TM-sulfides, phosphides and nitrides to metal-oxides or hydroxides has been reported in some recent studies in alkaline media for 
both ORR and oxygen evolution reaction (OER). ${ }^{12-15}$ For the acidic cases, due to limited stability of the corresponding oxide phases, a very little is understood about the evolution of the T-M-X surfaces at oxidizing potentials and corresponding theoretical investigation of the active surface/sites has been limited. ${ }^{16,17}$ Actually, the true active site of these catalysts is still not known theoretically. Therefore, from theoretical perspective, it is also crucial to correlate the surface electrochemistry and ORR activity of these promising T-M-X catalysts.

Electrochemical lithium (Li) tuning, by means of Li-ion intercalation and extraction in battery cells, represents a unique and general approach capable of tuning the physicochemical properties of existing catalysts in organic electrolyte. ${ }^{18}$ Previously our group has applied this method to tune layered material catalysts, including $\mathrm{MoS}_{2}$ and $\mathrm{LiCoO}_{2}$, olivine-type $\mathrm{Li}$ transition-metal phosphates $\left(\mathrm{LiMPO}_{4}\right)$ and transition-metal oxides, to obtain enhanced catalytic activity for hydrogen evolution reaction (HER) and OER, respectively. ${ }^{18-21}$ Such increased activity was explained in the case of $\mathrm{LiCoO}_{2}$ via electronic changes of the catalytically active Co edges-sites. ${ }^{22}$ Recently, for ORR, this method was first applied for the direct and continuous change of the lattice strain of Pt catalyst and thus controllable ORR catalytic activity. ${ }^{23}$ This finding has sparked our interest in Li tuning of T-M-X for advanced Pt-free ORR electrocatalysts.

In this work, with $\mathrm{CoS}_{2}$ as a representing material, enhanced ORR catalytic behavior of T-M-X was achieved through $\mathrm{Li}$ electrochemical tuning, accompanied by the mechanism understanding of its intrinsic activity from the density functional theory (DFT) calculations (for details refer to the Supporting Information). The Li galvanostatic cycling of commercial $\mathrm{CoS}_{2}$ (henceforth denoted as C$\mathrm{CoS}_{2}$ below) could result in much smaller $\mathrm{CoS}_{2}$ particles (denoted as LiET-CoS 2 below) with increased grain boundaries that may lead to better ORR performance. As expected, the experimental results show that the LiET-CoS 2 exhibited enhanced ORR activities as compared to the C-CoS 2 . Then we performed calculations of thermodynamics of the four-electron ORR mechanism for $\mathrm{CoS}_{2}$ surfaces as function of applied potential. The calculated evolution of the surfaces and its effect on calculated activity were 
compared to experiments and known standards such as $\mathrm{Pt}$ (111) and $\mathrm{Au}$ (111). In addition, our calculations propose a formation of a strongly stabilized $\mathrm{CoS}_{2} \mid \mathrm{CoOOH}$ interface with conducting $\mathrm{CoS}_{2}$ acting as support. To demonstrate the general efficacy of this method, $\mathrm{CoS}$ and $\mathrm{Ni}_{3} \mathrm{~S}_{2}$ were further subjected to lithium galvanostatic cycling and enhanced performance was also achieved. To our knowledge, there has been no report on electrochemical tuning of T-M-X as enhanced ORR catalysts, and this combined experimental and theoretical study represents a first step toward development and understanding of these catalysts. We envision this work will ignite general interest in future improvement of various T-M-X and their based hybrid ORR catalysts.

\section{RESULTS AND DISCUSSION}

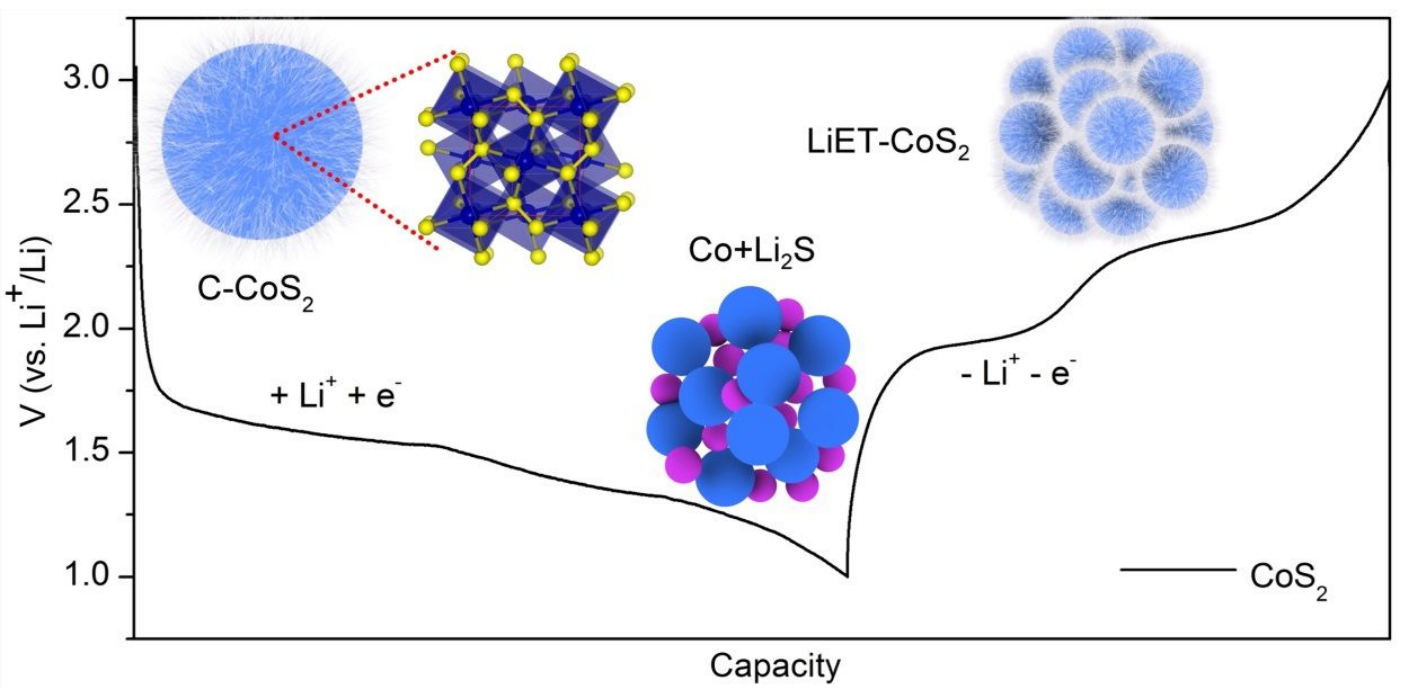

Figure 1. The galvanostatic cycling profile of $\mathrm{CoS}_{2}$ sample. The pouch battery was discharged/charged to $1.0 \mathrm{~V} / 3.0 \mathrm{~V}$ (vs. $\mathrm{Li}^{+} / \mathrm{Li}$ ) with small charge/discharge current of $100 \mu \mathrm{A}$ to maximally maintain the integration of the particles. Inset: schematic of electrochemical tuning process of galvanostatic lithiation (charge) and delithiation (discharge) process, during which $\mathrm{CoS}_{2}$ morphology change from single crystalline $\left(\mathrm{C}-\mathrm{CoS}_{2}\right)$ to the hybrid of $\mathrm{Co}$ and $\mathrm{Li}_{2} \mathrm{~S}\left(\mathrm{Co}+\mathrm{Li}_{2} \mathrm{~S}\right)$, and then to small interconnected crystalline sample $\left(\mathrm{LiET}-\mathrm{CoS}_{2}\right)$. Also shown is the bulk cubic structure of pyrite $\mathrm{CoS}_{2}$.

The electrochemical tuning process of galvanostatic lithiation (charge) and delithiation (discharge) has been applied to $\mathrm{CoS}_{2}$ as schematically illustrated in Figure 1. Specifically, C-CoS 2 slurry was made according to previous method and then drop casted onto $\mathrm{Cu}$ foil substrate and assembled into a lithium- 
ion battery pouch cell as the cathode, with $\mathrm{Li}$ metal as the anode and $1 \mathrm{M} \mathrm{LiPF}_{6}$ in $1: 1 \mathrm{w} / \mathrm{w}$ ethylene carbonate/diethyl carbonate as the electrolyte. Previous reports on lithium-ion batteries demonstrated that the conversion reaction mechanism of sulfides with $\mathrm{Li}^{+}$is same as that of oxides $\left(\mathrm{M}^{\mathrm{n}+} \mathrm{X}+n \mathrm{e}^{-}+\right.$ $n \mathrm{Li}^{+} \Leftrightarrow \mathrm{M}^{0}+n \mathrm{Li}(\mathrm{X})(\mathrm{X}=\mathrm{S}$ or $\mathrm{O})$. For $\mathrm{CoS}_{2}$ the reaction proceeds as: $\mathrm{CoS}_{2}+4 \mathrm{Li}^{+}+4 \mathrm{e}^{-} \Leftrightarrow \mathrm{Co}+$ $2 \mathrm{Li}_{2} \mathrm{~S}$, where the $\mathrm{Co}-\mathrm{S}$ bonds are broken due to $\mathrm{Li}_{2} \mathrm{~S}$ formation during lithiation and will be rebuilt during delithiation. According to the mechanism proposed by Poizot et al., ${ }^{24}$ Gibbs free energy change $(\Delta \mathrm{G})$ and electromotive force (emf, $E$ ) values of this reaction were also calculated as $-146 \mathrm{~kJ}$ mol and $1.898 \mathrm{~V}$, respectively, indicating that the reduction process is thermodynamically spontaneously feasible. $^{25}$ As illustrated, the extraction of lithium leads to the formation of much smaller, but interconnected $\mathrm{LiET}-\mathrm{CoS}_{2}$. In addition to increasing the surface area, this morphological transformation also increases the formation of grain boundaries that are hypothesized to be active sites for ORR. Further, as $\mathrm{CoS}_{2}$ surface has been shown to be passivated by a surface oxide film under ambient atmosphere, we expect enhanced surface oxidation due to the increased grain boundaries. This procedure was repeated for other sulfides (i.e. $\mathrm{CoS}$ and $\mathrm{Ni}_{3} \mathrm{~S}_{2}$, see Figure $\mathrm{S} 1$ and $\mathrm{S} 2$ in Supporting Information). 
a
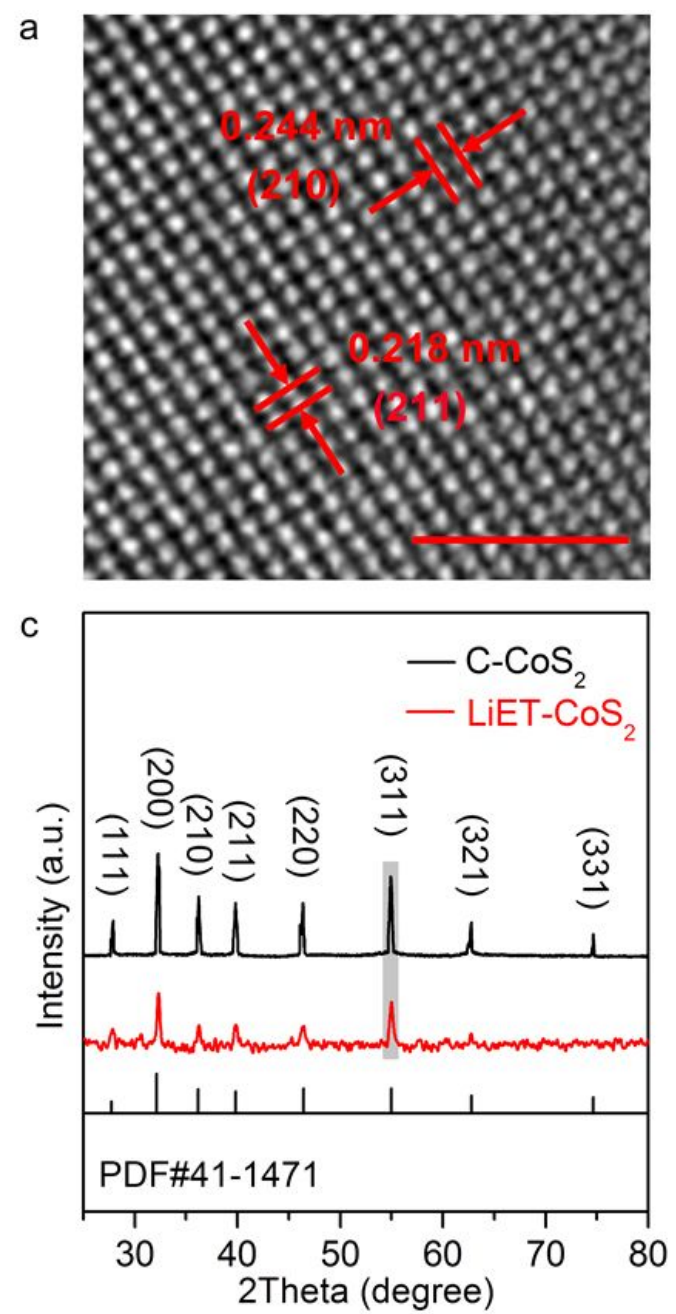

$b$
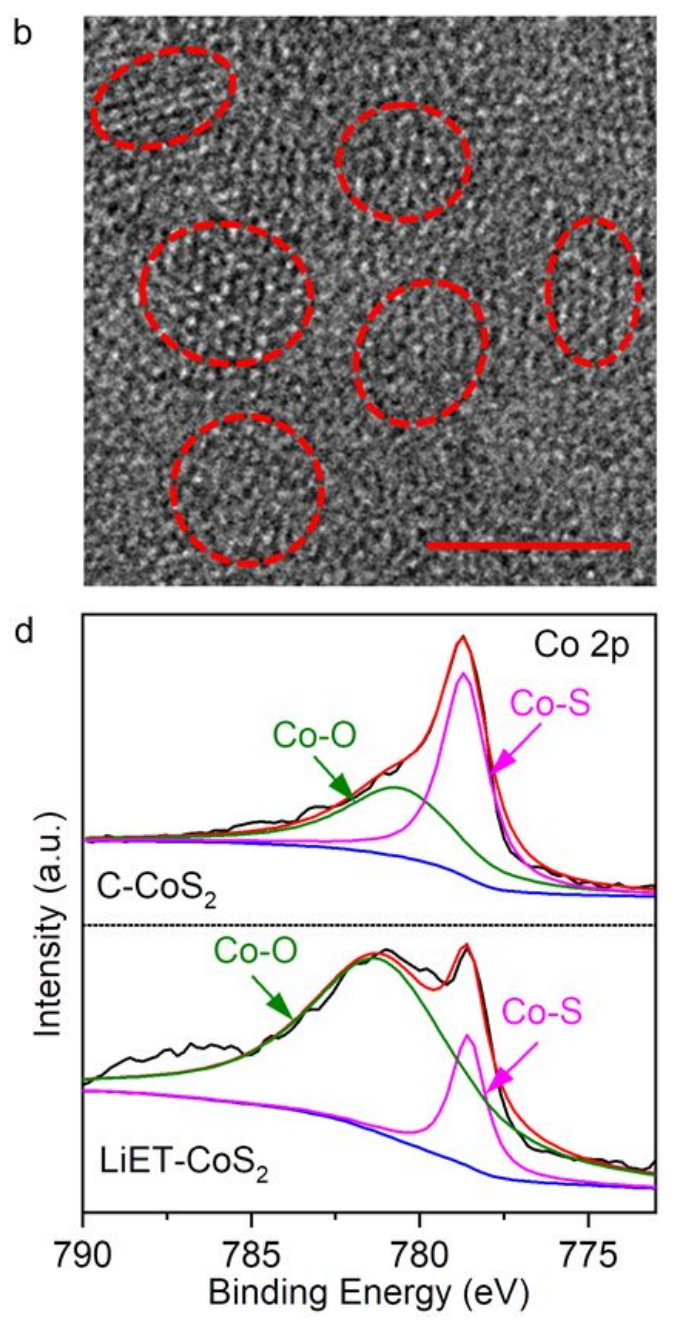

Figure 2. Characterizations of C-CoS 2 and LiET-CoS 2 before voltammetry measurements. (a) Representative TEM image of $\mathrm{C}-\mathrm{CoS}_{2}$. The lattice structure demonstrated the single-crystalline nature of the pristine particle with preferentially exposed (210) and (211) surface. (b) TEM image of LiET-CoS 2 exhibited lattice distortion galvanostatic cycling. The scales in Figure $2 \mathrm{a}$ and $2 \mathrm{~b}$ are $2 \mathrm{~nm}$ and $4 \mathrm{~nm}$, respectively. (c) Powder XRD patterns of C-CoS $\mathrm{S}_{2}$ and LiET-CoS 2 . Both samples were typical cubic XRD structures (PDF \# 41-1471), but LiET-CoS 2 possessed a broader peak feature than C-CoS 2 . (d) XPS spectra of C-CoS 2 and LiET-CoS 2 . The strength of Co-O peak of LiET-CoS 2 enhanced as compared to that of $\mathrm{C}-\mathrm{CoS}_{2}$ indicating higher surface oxidation.

Characterization of the catalyst. Transmission electron microscopy (TEM), X-ray powder Diffraction (XRD) and X-ray photoelectron spectroscopy (XPS) were then employed to characterize the C-CoS 2 and LiET-CoS 2 . As shown in Figure 2a, TEM of C-CoS 2 shows the monocrystalline features of pristine $\mathrm{CoS}_{2}$. The spacing of (210) and (211) atomic planes were determined as $0.244 \mathrm{~nm}$ and 0.218 $\mathrm{nm}$, respectively. After the Li tuning, as depicted in Figure 2b, the morphology of LiET-CoS 2 exhibited 
significant change as demonstrated by the obvious blurred areas. While the original lattices are still visible, their border was obscure compared with pristine $\mathrm{C}-\mathrm{CoS}_{2}$. More significantly, the lattice expansion and contraction in the galvanostatic cycles has rendered a number of small lattice domains with altered orientations and new GBs. These GBs are generally rich of lattice defects, dislocations, distortions, or local strains with distinct atomic structures, which are essential for significantly enhanced catalytic activity likely due to higher concertation of the undercoordinated edge-sites. ${ }^{19,20}$ The crystal structures of the C-CoS 2 and as-tuned LiET-CoS 2 were then identified by XRD with the results shown in Figure 2c. The XRD pattern of the C-CoS 2 possessed sharp diffraction peaks that can be assigned to a cubic pyrite phase with a space group of Pa-3 (JCPDS card No. 41-1471), and the strong peaks also indicated high crystallinity and purity of the C-CoS 2 samples. For LiET-CoS 2 , the strengths of all the peaks weakened, and its peak width at half maximum (FWHM) at (311) crystal plane (as marked grey) were determined as 0.305 , as compared to 0.279 of C- $\mathrm{CoS}_{2}$, indicating the inferior crystallinity integrity and averagely smaller size of the as-tuned sample. We also note that despite the lower crystallinity of LiET-CoS 2 , its XRD pattern is much closer to that of $\mathrm{C}-\mathrm{CoS}_{2}$ than to layered $\mathrm{LiCoS}_{2} \cdot{ }^{26} \mathrm{XPS}$ was further performed to study the surface chemical compositions and oxidation states of the samples with a $\mathrm{C} 1 \mathrm{~s}$ binding energy of $284.6 \mathrm{eV}$ as the internal marked standard. As shown in Figure $2 \mathrm{~d}$, the broad Co regions in both the two spectra are deconvoluted into red and green peaks, corresponding to Co-S and Co-O peaks, respectively. Consistent with our prediction, the LiET-CoS $(\mathrm{Co}-\mathrm{O}: \mathrm{Co}-\mathrm{S}=83.4: 16.6)$ shows higher intensity Co-O peak as compared to $\mathrm{C}-\mathrm{CoS}_{2}(\mathrm{Co}-\mathrm{O}: \mathrm{Co}-\mathrm{S}=45.0: 55.0)$, which can be attributed to the higher liability for surface oxidation after the galvanostatic cycles. This finding is also supported by our DFT calculations below. For $\mathrm{CoS}$ and $\mathrm{Ni}_{3} \mathrm{~S}_{2}$, similar results were also observed and discussed with Figure S3-S4 in the Supporting Information. 
a

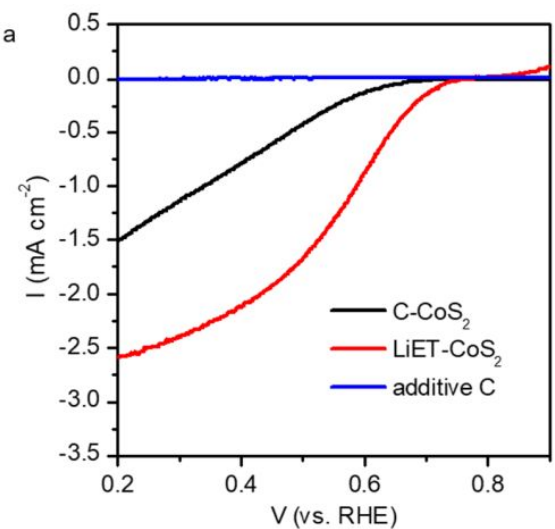

c

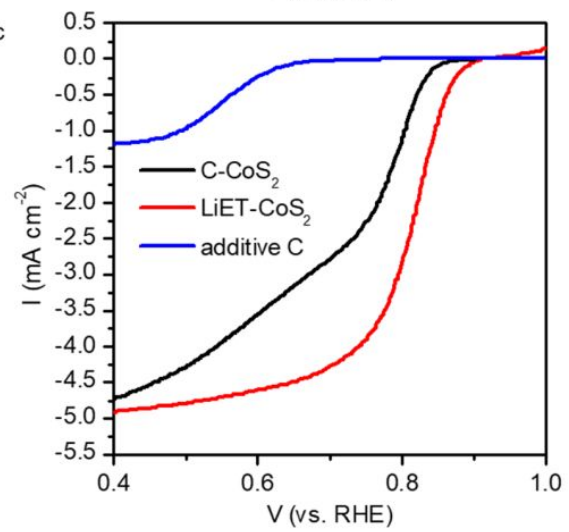

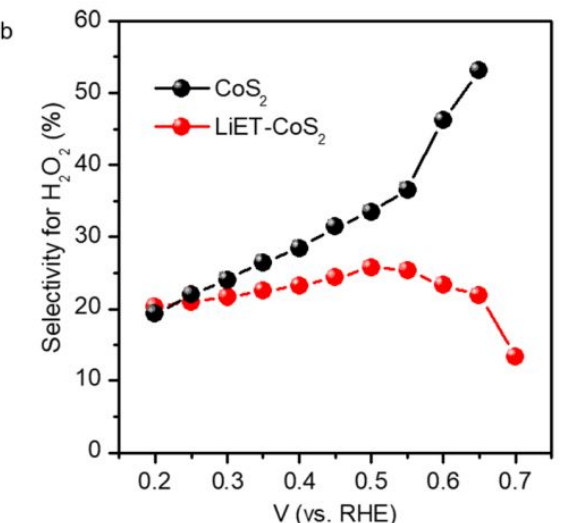

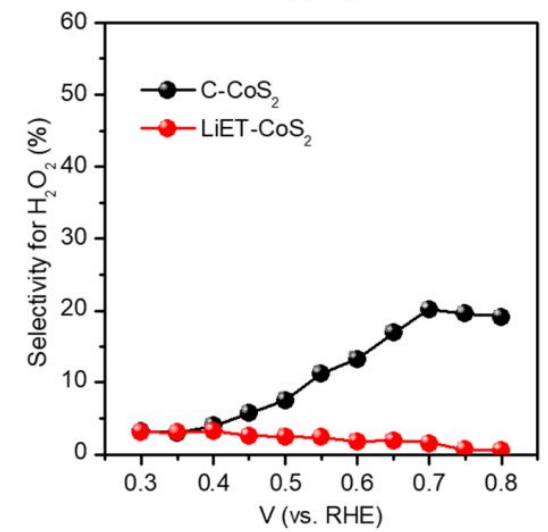

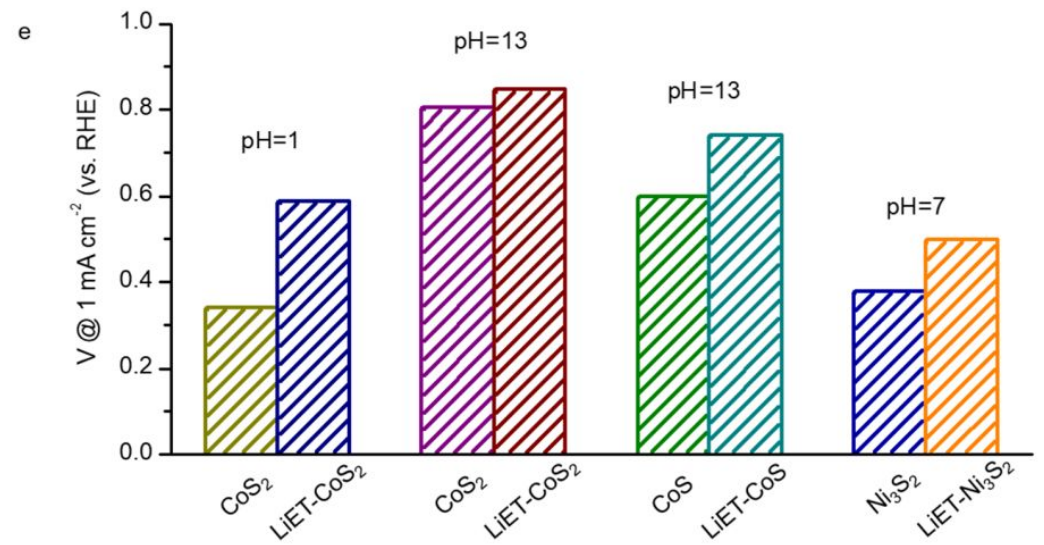

Figure 3. ORR performance of the pristine and tuned samples. (a) RRDE curves of C-CoS $\mathrm{C}_{2}$ and $\mathrm{LiET}^{-\mathrm{CoS}_{2}}$ at a rotation rate of $1600 \mathrm{rpm}$ in $\mathrm{O}_{2}$-saturated $0.1 \mathrm{M} \mathrm{HClO}_{4}(\mathrm{pH}=1)$ with a sweep rate of $10 \mathrm{mVs}^{-1}$. (b) The corresponding selectivity for $\mathrm{H}_{2} \mathrm{O}_{2}(\%)$ at different potentials. (c) RRDE curves of C-CoS 2 and $\mathrm{LiET}-\mathrm{CoS}_{2}$ at a rotation rate of 1600 rpm in $\mathrm{O}_{2}$-saturated $0.1 \mathrm{M} \mathrm{KOH}(\mathrm{pH}=13)$ with a sweep rate of $10 \mathrm{mVs}^{-1}$. (d) The corresponding selectivity for $\mathrm{H}_{2} \mathrm{O}_{2}$ (\%) at different potentials. (e) The performance comparison of pristine and tuned $\mathrm{CoS}_{2}, \mathrm{CoS}$ and $\mathrm{Ni}_{3} \mathrm{~S}_{2}$ samples at the current intensity of $1 \mathrm{~mA} \mathrm{~cm}^{-2}$ at specific $\mathrm{pH}$ condition.

ORR performance and $\mathrm{H}_{2} \mathrm{O}_{2}$ selectivity. Rotating ring disk electrode (RRDE) experiments were performed to study the ORR kinetics of the pristine and LiET-CoS 2 samples. As shown in Figure 3a, in 
$0.1 \mathrm{M} \mathrm{HClO}_{4}$ and at $1600 \mathrm{rpm}$, the polarization curve recorded with the $\mathrm{C}-\mathrm{CoS}_{2}$ showed an onset potential at $\sim 0.65 \mathrm{~V}$ versus RHE, beyond which the cathodic current rose slowly by applying higher overpotential (ca. a current density of $1.0 \mathrm{~mA} \mathrm{~cm}{ }^{-2}$ at $\sim 0.35 \mathrm{~V}$ versus RHE). In sharp contrast, with same mass loading but with higher surface area, the LiET-CoS 2 exhibited markedly enhanced ORR activity with an improved onset potential of $\sim 0.78 \mathrm{~V}$ and faster current increase (ca. a current density of $1.0 \mathrm{~mA} \mathrm{~cm}-2$ at $\sim 0.59 \mathrm{~V}$ versus $\mathrm{RHE})$. The selectivity of two-electron reduction $\left(\mathrm{H}_{2} \mathrm{O}_{2}\right.$ production $)$ process was quantified using RRDE curves in Figure $3 \mathrm{~b}$ and Figure S5. As shown, C-CoS 2 is selective towards two-electron ( $52 \% \mathrm{H}_{2} \mathrm{O}_{2}$ at $0.65 \mathrm{~V}$ vs. RHE) and the selectively decreases at higher overpotentials (20\% at $0.2 \mathrm{~V}$ vs. RHE). The results for $\mathrm{LiET}-\mathrm{CoS}_{2}$ are qualitatively different, where a low selectivity towards $\mathrm{H}_{2} \mathrm{O}_{2}(<25 \%)$ is observed over the entire potential range. The ORR performance of the samples in alkaline solution was examined and analogous trends are presented in Figure $3 \mathrm{c}$ and $3 \mathrm{~d}$. As shown, the LiET-CoS $\mathrm{C}_{2}$ sample exhibited a lower $\mathrm{H}_{2} \mathrm{O}_{2}$ selectivity $(<3 \%)$ compared to the C-CoS sample (5-20\%). The significantly lower $\mathrm{H}_{2} \mathrm{O}_{2}$ selectivity observed in alkaline and acidic conditions suggests the differences in the active surface at different $\mathrm{pH}$, which is consistent with our DFT calculations presented later. As the polarization curves in Figure 3a and 3c use similar mass loadings, it is necessary to normalize the performance to the electrochemical surface area (ESA). The ESA of the samples prior to and after Li tuning was calculated using the electric double layer capacitance (EDLC). Although the re-normalized results (see Figure S6 of Supporting Information) also show improved performance of $\mathrm{LiET}-\mathrm{CoS}_{2}$ over the $\mathrm{C}-\mathrm{CoS}_{2}$ (indicating the creation of more active sites as the result of $\mathrm{LiET}$ ), we note that the major outcome of LiET is the increase in the surface area due to formation of smaller particles. The efficacy of this method is demonstrated by analogous experiments for $\mathrm{CoS}$ and $\mathrm{Ni}_{3} \mathrm{~S}_{2}$. As summarized in Figure 3e, improved ORR performance is observed for both LiET-CoS (in alkaline medium) and $\mathrm{LiET}-\mathrm{Ni}_{3} \mathrm{~S}_{2}$ (at neutral $\mathrm{pH}$ ), indicating the general applicability of this method. 
Structural evolution of the Catalyst under ORR. The surface structure of the catalyst after ORR cycling (1-2K cycles from 0.2 to $1.0 \mathrm{~V}$ vs. RHE) in acid and base was studied by XPS, bulk Pourbaix analysis and DFT methods (see Figures 4a-d). In alkaline solution, the deconvoluted peaks for $\mathrm{CoS}_{2}$ (labeled as Co-S) and $\mathrm{Co}(\mathrm{OH})_{2}$ (labeled as Co-O) indicate a significant presence of Co-O bonds on the surface for both the C-CoS 2 and LiET-CoS 2 samples (Figures 4a-b). However, in acidic solution, the samples after ORR cycling show a new feature at binding energy $782.9 \mathrm{eV}$ relative to the samples after ORR cycling in alkaline solution, which can be assigned as dissolved $\mathrm{Co}^{+2}$ in perchloric acid. This finding is in overall agreement of low $\mathrm{pH}$ instability of bulk $\mathrm{CoS}_{2}$ and Co-oxides as further discussed below. Consequently, the Co-O peak area is reduced in acidic solution relative to Co-S. In overall, alkaline conditions lead to the formation of surface oxides such as $\mathrm{Co}(\mathrm{OH})_{2}$ and $\mathrm{CoOOH}$ while the oxide dissolution is observed in acidic conditions.

Before evaluating the surface reactivity for ORR at the atomistic level, it is useful to discuss the stability of the Co-S-O system. Specifically, using the experimental free energies of formation for number of Co-O-H-S solid compounds and solvated species (see also Table S1), we construct the potential-pH Pourbaix diagram in Figure 4c. Assuming standard conditions (room temperature and ambient pressure) and typical concentrations of Co $\left(10^{-6} \mathrm{~kg} / \mathrm{mol}\right)$ and $\mathrm{S}\left(10^{-3} \mathrm{~kg} / \mathrm{mol}\right)$ species, ${ }^{27}$ we identify $\mathrm{CoS}_{2}$ to be stable over a narrow voltage range $(0-0.5 \mathrm{~V}$ vs. RHE) for the relevant $\mathrm{pH}$. Such analysis indicates that bulk $\mathrm{CoS}_{2}$ is thermodynamically unstable at potentials higher than $0.5 \mathrm{~V}$. However, high electronic conductivity of $\mathrm{CoS}_{2}$ allows for larger operational electrochemical stability as is known for other conductive materials such as $\mathrm{RuO}_{2}$, which are often stable electrocatalysts beyond Pourbaix limits. ${ }^{28}$ The stability window of $\mathrm{CoS}_{2}$ can therefore can be potentially much larger than $0-$ $0.5 \mathrm{~V}$ vs. RHE.

Additionally, XPS and XRD and stability tests that indicate the presence of $\mathrm{CoS}_{2}$ after ORR measurements, it is possible that the surface of the $\mathrm{CoS}_{2}$ is passivated by Co-O species and the dissolution process is kinetically limited. To test this hypothesis, we have examined the stability for a 
range $\mathrm{CoO}_{x} \mathrm{H}_{y}$ species (oxides, double/oxy-hydroxides) at various oxygen coverages on the most stable $\mathrm{CoS}_{2}(100)$ surface using DFT calculations. As the surface structure is likely to depend on $\mathrm{pH}$, we first discuss the alkaline condition results.

Alkaline conditions. At $\mathrm{pH}>8$ the situation is drastically different due to the formation of stable $\mathrm{Co}(\mathrm{OH})_{2}$ and $\mathrm{CoOOH}$ oxide phases that is facilitated by the small $4 \%$ lattice mismatch between $\mathrm{CoOOH}(\mathrm{Co}-\mathrm{Co}$ distance of $3.09 \AA)$ and $\mathrm{CoS}_{2}$-S terminated (100) surface (S-S distance of $3.22 \AA$ ). Compared to the S-terminated $\mathrm{CoS}_{2}(100)$ surface, the formation of the $\mathrm{CoOOH}(0001)$ overlayer leads to $\mathrm{a}-0.25 \mathrm{eV} / \mathrm{Co}$ stabilization and extending the potential window to $\sim 0.7 \mathrm{eV}$. Given the experimental onset of ORR is $\sim 0.8 \mathrm{~V}$ vs. RHE and the XPS results showing the high fraction of Co-O bonds on the surface, we propose that a passivating, thin $\mathrm{CoOOH}$ covers the $\mathrm{CoS}_{2}$ surface under alkaline conditions. Acidic conditions. At $\mathrm{pH}<8$ and $\mathrm{U}>0.5 \mathrm{~V}$ the dissolution of exposed $\mathrm{CoS}_{2}$ surface is expected (bulk Pourbaix diagram of Figure 4c), and any undissolved $\mathrm{CoS}_{2}$ is likely to be covered by oxygen adsorbates due to the strong $\mathrm{O}$ binding energy at S-sites $\left(\Delta \mathrm{G}_{\mathrm{O}}=1.45 \mathrm{eV}\right.$ on $\mathrm{S}$ terminated $\mathrm{CoS}_{2}(100)$, see Table S2). In contrast to the alkaline case, the formation of a Co-O phase is not likely due to low stability of solid oxide phases in acid and is consistent with XPS results that indicate dissolution and a lower fraction of Co-O features compared to both the alkaline $(\mathrm{Co}-\mathrm{O}: \mathrm{Co}-\mathrm{S}=44: 56)$ and as-synthesized $(\mathrm{Co}-\mathrm{O}: \mathrm{Co}-\mathrm{S}=$ 45:55) case. Our calculations for $\operatorname{CoS}_{2}$ (100) surface show (see Figure 4d) that a high coverage of adsorbed $\mathrm{O}^{*}(0.5 \mathrm{ML})$ on $\mathrm{CoS}_{2}$ surface (stable $\sim 0.5 \mathrm{~V}$ from Pourbaix diagram) is possible or that $\mathrm{S}$ substitution by $\mathrm{O}$ occurs at the surface $\left(2 \mathrm{~S} \rightarrow 2 \mathrm{O}, \mathrm{S}_{\text {term }}\right)$. Our attempts to increase the surface O coverage beyond $0.5 \mathrm{ML}$ led to drastic changes in the surface structure (desorption of $\mathrm{SO}_{2}{ }^{2-}$ species) indicating that this surface structure may be dynamic and occurs in parallel with the dissolution process. For CoS and $\mathrm{Ni}_{3} \mathrm{~S}_{2}$, similar results were also observed and discussed with Figure S3-S4 in the SI. 
a

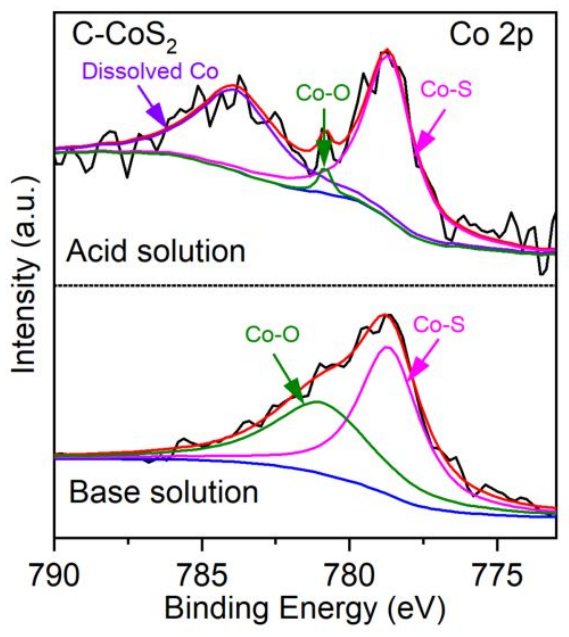

C

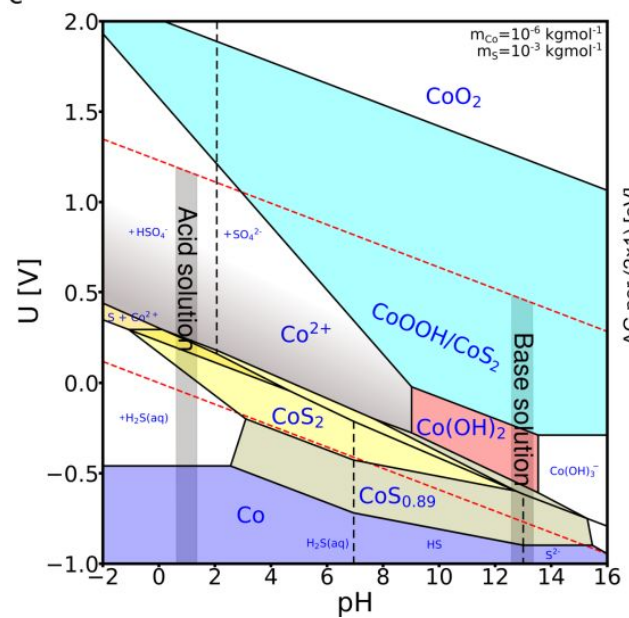

b

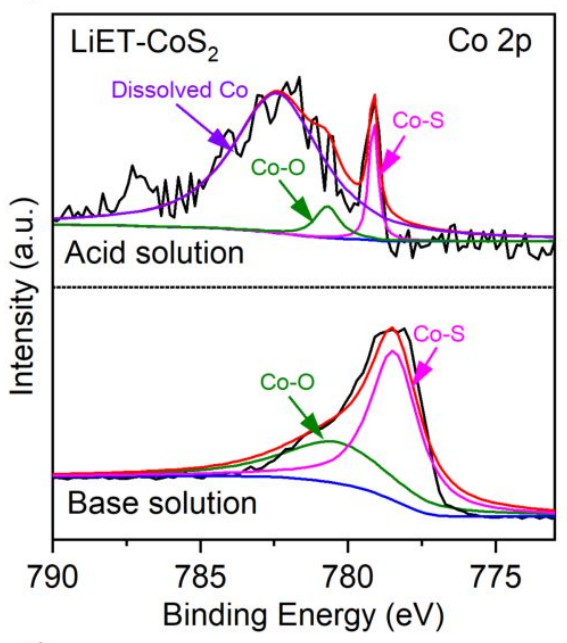

d

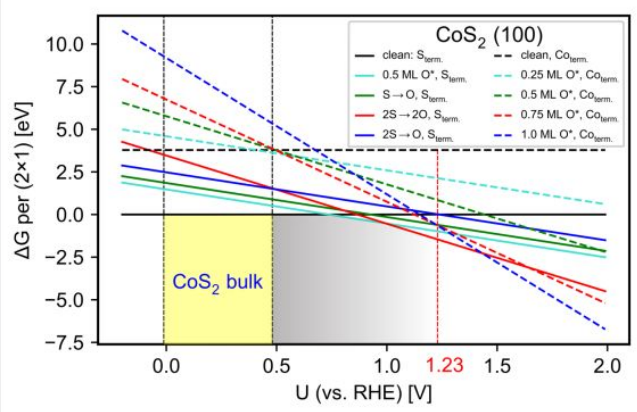

Figure 4. Observed XPS changes after ORR and the thermodynamics of the $\mathrm{CoS}_{2}$ system under applied voltage and pH. XPS spectra of (a) C-CoS 2 and (b) LiET- $\mathrm{CoS}_{2}$ samples in acidic and base solution after ORR CV-voltammetry which indicate the presence of Co-O bond formation with values indicating peak ratios. For similar data for $\mathrm{Ni}_{3} \mathrm{~S}_{4}$ and $\mathrm{CoS}$ please refer to Figures S3 and S4. (c) Bulk Pourbaix (pH-Voltage) diagram of the Co-O-S $+\mathrm{H}_{2} \mathrm{O}$ system at concentrations of $10^{-6} \mathrm{~kg} / \mathrm{mol}$ and $10^{-3} \mathrm{~kg} / \mathrm{mol}$ for cobalt and sulfur and at standard conditions. The stabilities of the solid phases (shown in color) relative to solvated phases is based on experimental free energies from Ref. ${ }^{29}$ For $\mathrm{CoOOH}$, we add $-0.25 \mathrm{eV}$ as our calculated estimated of surface stabilization energy due to $\mathrm{CoS}_{2}$ (100) support (see SI for details). The support free Pourbaix diagram is shown in Figure S8. Due to more clarity, we omit the $\mathrm{Co}_{3} \mathrm{~S}_{4}$ phase which overlaps with $\mathrm{CoS}_{2}$. The region relevant to our ORR/CV measurement is highlighted in grey for low and high pH. (d) Calculated Surface Pourbaix Diagram of $\operatorname{CoS}_{2}(100)$ surfaces. We have considered both the S-terminated $\left(\mathrm{S}_{\text {term. }}\right)$ and Co-metal $\left(\mathrm{Co}_{\text {term. }}\right)$ terminations of the (100). For ORR Voltage window, the most stable terminations are 
clean $\mathrm{S}_{\text {term. }}, 0.5 \mathrm{ML}$ O-adsorbed $\mathrm{S}_{\text {term. }}$ surface $\left(0.5 \mathrm{ML} \mathrm{O}, \mathrm{S}_{\text {term. }}\right)$ and $\mathrm{S}_{\text {term. }} 0.5 \mathrm{ML} \mathrm{O}$ substituted surface $(2 \mathrm{~S} \rightarrow 2 \mathrm{O}$, $\left.\mathrm{S}_{\text {term. }}\right)$.

Calculated ORR activities. Having identified the possible surface structures in alkaline and acidic media, the next step is to evaluate their ORR activity using the computational hydrogen electrode (CHE) approach. ${ }^{30}$ In addition to the most stable surface structures from Figure 4 d, we have also considered $\mathrm{CoS}_{2}$ (110), $\mathrm{CoS}_{2}$ (210)-S terminated as well as $\mathrm{CoS}_{2}$ (100) supported CoOOH overlayers and nanostripes. We highlight their structures at the end of a potential limiting step (PLS) in Figure 5a and Table S2. For individual surface Pourbaix analysis of stable surface terminations of $\mathrm{CoS}_{2}$ see SI Figures S9-10.

We have calculated the ORR activities assuming a most common single-site associative four electron/proton ORR mechanism, where the $\mathrm{pH}$ independent theoretical overpotential can be easily obtained from calculated free-energies of $\Delta \mathrm{G}_{\mathrm{O}^{*},} \Delta \mathrm{G}_{\mathrm{OH}^{*}}$ and $\Delta \mathrm{G}_{\mathrm{OOH}^{*}}$ intermediates as:

$\eta_{\text {Theory }}=\max \left[\Delta \mathrm{G}_{\mathrm{OOH} *}-4.92 \mathrm{eV}, \Delta \mathrm{G}_{\mathrm{O} *}-\Delta \mathrm{G}_{\mathrm{OOH} *}, \Delta \mathrm{G}_{\mathrm{OH} *}-\Delta \mathrm{G}_{\mathrm{O} *},-\Delta \mathrm{G}_{\mathrm{OH} *}\right] / \mathrm{e}+1.23 \mathrm{~V}$

The lower ORR theoretical overpotential directly implies higher limiting ORR potential $U_{\text {ORR }}$ defined simply as $U_{O R R}=1.23 \mathrm{~V}-\eta_{\text {Theory }}$ which has been demonstrated to be comparable to measured onset potentials for many systems. ${ }^{31}$

In Figure $5 \mathrm{~b}$ we have summarized all the calculated $U_{O R R}$ limiting potentials for above considered surfaces as function of single energy descriptor, the $\Delta \mathrm{G}_{\mathrm{OH}}$ * energy. For ORR, the dependence on a single descriptor is approximate because our calculated free-energies follow the wellknown universal scaling between $\Delta \mathrm{G}_{\mathrm{OOH} *}=\Delta \mathrm{G}_{\mathrm{OH} *}+3.2$ (2) for ORR intermediates ${ }^{35}$ (shown as Figure S11), but not all $\eta_{\text {Theory }}$ is given only by either the first step $\left(\mathrm{O}_{2} \rightarrow \mathrm{OOH}^{*}\right)$ or last step $\left(\mathrm{OH}^{*} \rightarrow \mathrm{H}_{2}\right.$ 0) of the ORR mechanism. Nevertheless, the resulting single descriptor plot of Figure 5b has a welldefined volcano shape. For complete list of $\Delta \mathrm{G}_{\mathrm{O}^{*},} \Delta \mathrm{G}_{\mathrm{OH}^{*}}$ and $\Delta \mathrm{G}_{\mathrm{OOH}^{*}}$ and $\eta_{\text {Theory }}$ and details about the free energy calculations please refer to Table S2-3 of SI. All structures are also available online at 
catalysis-hub.org. ${ }^{36,37}$ The calculated overpotentials for the $\mathrm{CoS}_{2}$ (100) surfaces (circle symbols) are compared to $\mathrm{CoS}_{2}$ supported and unsupported edge-site activity of $1 \mathrm{ML} \mathrm{CoOOH}$ and $2 \mathrm{ML} \mathrm{CoOOH}$ nanostripes (NS) (square symbols). Please note, that due to the S-O bonding with $\mathrm{CoS}_{2}$ support, both 1 ML and $2 \mathrm{ML} \mathrm{CoOOH}$ nanostripes have Co-metal sites in $\mathrm{Co}^{+2}$ rather than $\mathrm{Co}^{+3}$ oxidation state.

The results for unsupported NS of $\mathrm{Co}^{+2}(\mathrm{OH})_{2}$ and $\mathrm{Co}^{+3} \mathrm{OOH}$ are adapted from our recent study. ${ }^{33}$ For $\mathrm{CoOOH} / \mathrm{CoS}_{2}$ we have also tested the activity of the basal plane site of the NS (triangle), which binds significantly stronger than edge site. Lastly, we compare the above calculated values to wellestablished calculated values for Pt (111) and $\mathrm{Au}$ (111) systems (star symbols), ${ }^{31}$ for which both the activity and selectivity toward $\mathrm{H}_{2} \mathrm{O}_{2}$ is known experimentally.

The calculated $U_{O R R}$ potentials from Eq. 1 shown in Figure 5b. lead to following trends for the activity of the $\mathrm{CoS}_{2}-\mathrm{H}_{2} \mathrm{O}$ system. When terminal sulfur is the active site for ORR as is the case for clean: $\mathrm{CoS}_{2}-\mathrm{S}_{\text {term. }}, \mathrm{S}_{\text {sub }} \rightarrow \mathrm{O}: \mathrm{CoS}_{2}-\mathrm{S}_{\text {term. }}$ and for $0.5 \mathrm{ML} \mathrm{O}_{\text {ads. }}: \mathrm{CoS}_{2}-\mathrm{S}_{\text {term. }}$ (100) surfaces (for structures see Figure 5a), the activity is quite low due to unfavorable $\mathrm{O}^{*} \rightarrow \mathrm{OH}$ potential limiting step. While the activity of the three corresponding surfaces is improving with increasing oxygen content at the surface $\left(\mathrm{U}_{\mathrm{ORR}}=-0.12,0.0,0.18 \mathrm{~V}\right)$ it does not reache the experimentally observed onset potentials at any $\mathrm{pH}$. As we have shown in Figure 4c, higher anodic potentials will lead to either i) increase of oxygen coverage beyond $0.5 \mathrm{ML}$ coverage or ii) to greater substitution of S-atoms by oxygen labeled as $2 \mathrm{~S}_{\text {sub }} \rightarrow 2 \mathrm{O}$ : $\mathrm{CoS}_{2}-\mathrm{S}_{\text {term. }}$. We have already discussed that i) leads to unstable surface and formation of $\mathrm{SO}_{2}^{-}$, and ii) results in the change of the active site from sulfur site to cobalt site with much improved $\mathrm{U}_{\mathrm{ORR}}=0.43 \mathrm{~V}$ $\left(\mathrm{O}^{*} \rightarrow \mathrm{OH}\right.$ PLS, Table S2). Increasing further the sulfur substitution by oxygen leads essentially to Cometal terminated surface $\left(\mathrm{CoS}_{2}-\mathrm{Co}_{\text {term. }}\right.$ in Figure 5a) which is marginally less stable than $2 \mathrm{~S}_{\text {sub }} \rightarrow 2 \mathrm{O}$ : $\mathrm{CoS}_{2}-\mathrm{S}_{\text {term. }}$ (as shown in Figure 4c). Because the active site has now fully switched to Co-metal, the calculated onset potential is vastly improved to $\mathrm{U}_{\mathrm{ORR}}=0.61 \mathrm{~V}$ and the PLS has changed to $\mathrm{O}_{2} \rightarrow \mathrm{OOH}$. Also shown in Figure 5b are the results for (110) and stepped (210) surfaces, where again Co-metal is the active site with $\mathrm{U}_{\mathrm{ORR}}=0.22\left(\mathrm{OH}^{*} \rightarrow \mathrm{H}_{2} \mathrm{O}\right.$ PLS $)$ and $0.38 \mathrm{~V}\left(\mathrm{O}_{2} \rightarrow \mathrm{OOH}\right.$ PLS $)$. Based on stability 
analysis of Figures $4 \mathrm{~b}-\mathrm{c}$, we estimate that a more stable $2 \mathrm{~S}_{\mathrm{sub}} \rightarrow 2 \mathrm{O}: \mathrm{CoS}_{2}-\mathrm{S}_{\text {term. }}$ (100) surface or stepped (210) surface is responsible for intrinsic activity of the $\mathrm{CoS}_{2}$ system at acidic $\mathrm{pH}$. The calculated $\mathrm{U}_{\mathrm{ORR}}$ values of 0.43 and $0.38 \mathrm{~V}$ compare well with the experimental onset potential values of $0.33 \mathrm{~V}$ for $\mathrm{C}-\mathrm{CoS}_{2}$ in acidic solution (Figure 3c) further supporting the fact that Co-metal site within the $\mathrm{CoS}_{2}$ is responsible for intrinsic activity of $\mathrm{CoS}_{2}$ in acidic solution.

Under alkaline $\mathrm{pH}$, potentials as low as $0.5 \mathrm{~V}$ lead to preferential formation of $\mathrm{Co}(\mathrm{OH})_{2}$ and $\mathrm{CoOOH}$ bulk phases and their nanostripe versions supported on $\mathrm{CoS}_{2}$, as already discussed above (see Figure 4b). We have recently published the calculated onset potentials at the edge-sites of unsupported $\mathrm{Co}(\mathrm{OH})_{2}$ and $\mathrm{CoOOH}$ nanostripes, which are $0.67 \mathrm{~V}$ and $0.46 \mathrm{~V}$, respectively. Supporting a double monolayer of $\mathrm{CoO}+\mathrm{CoOOH}$ on $\mathrm{CoS}_{2}\left(2 \mathrm{ML} \mathrm{CoOOH} / \mathrm{CoS}_{2}\right.$ in Figure $\left.5 \mathrm{~b}\right)$ or a single monolayer of $\mathrm{CoOOH}$ on $\mathrm{CoS}_{2}\left(\mathrm{CoOOH} / \mathrm{CoS}_{2}\right.$ in Figure 5b) has a synergistic effect on the ORR activities of the Cooxides when Co-edge sites are considered, with the onset overpotentials are $0.58 \mathrm{~V}$ and $0.74 \mathrm{~V}$ respectively $\left(\mathrm{O}_{2} \rightarrow \mathrm{OOH}\right.$ PLS $)$. The exposed Co-metal edge sites with Co-oxide systems are clearly superior ORR active to sulfur sites in $\mathrm{CoS}_{2}$ system. Again, the above calculated $U_{O R R}$ values compare well with the experimental values of $0.8 \mathrm{~V}$ for $\mathrm{C}-\mathrm{CoS}_{2}$ in alkaline solution (see Figure $3 \mathrm{c}$ ) further supporting the fact that Co-metal site within the Co-oxide is responsible for intrinsic activity of $\mathrm{CoS}_{2}$ in alkaline solution.

Next, we turn our attention to the position of our calculated points at the theoretical volcano of Figure 5b relative to $\mathrm{Pt}(111)$ and $\mathrm{Au}$ (111) points. Experimentally, it is known that $\mathrm{Pt}(111)$ is highly selective towards $4 \mathrm{e}-/ 4 \mathrm{H}^{+}$ORR while $\mathrm{Au}$ (111) strongly prefers $2 \mathrm{e}^{-} / 2 \mathrm{H}^{+} \mathrm{H}_{2} \mathrm{O}_{2}$ evolution. The high selectivity of LiET-CoS 2 towards $4 \mathrm{e}-/ 4 \mathrm{H}^{+}$ORR in alkaline solution (see Figure $3 \mathrm{~b}$ ) must originate due to Co-metal edge sites in Co-oxides which are approaching the Pt (111) point on our theoretical volcano. 
a

Acid solution

Base solution

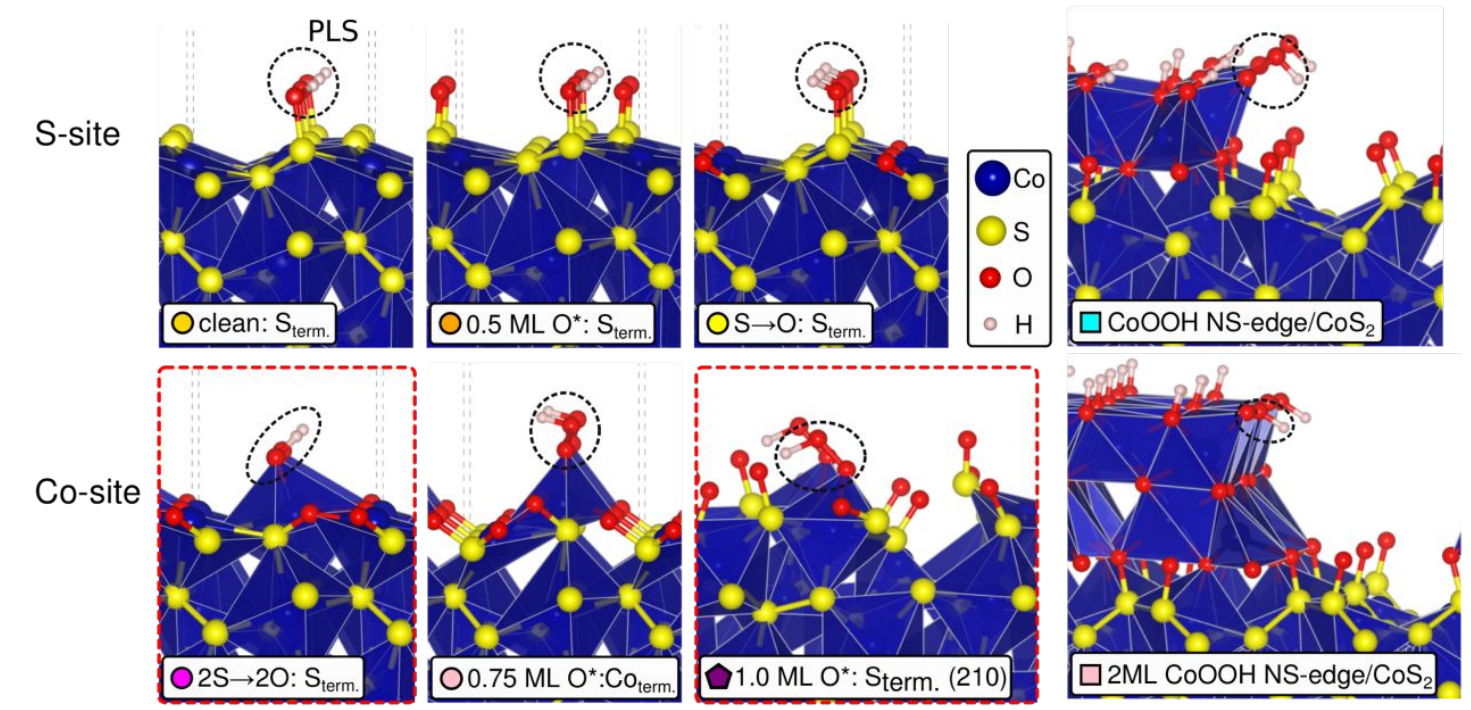

b

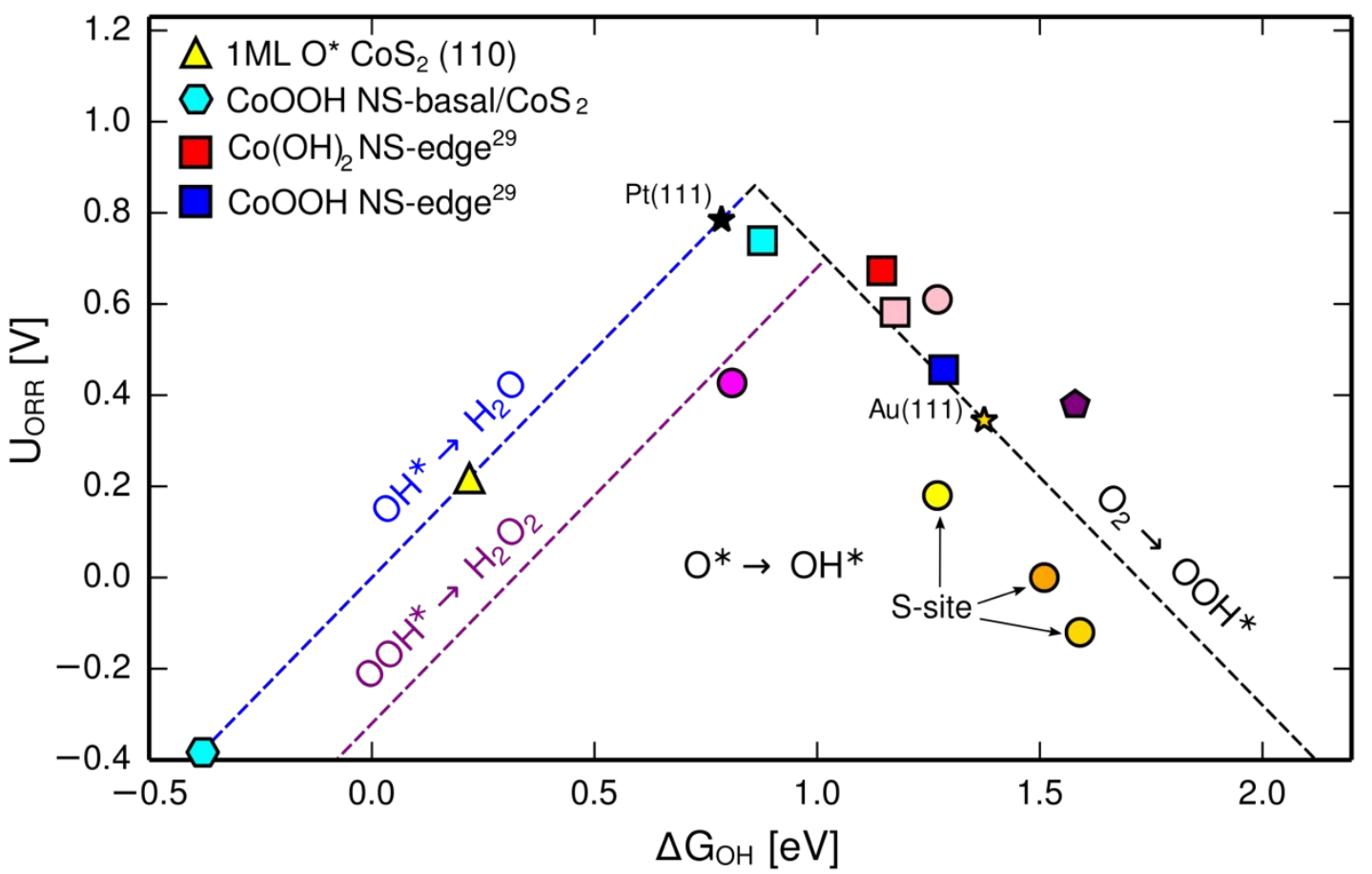

Figure 5. Considered surfaces and their calculated ORR activities as function of $\mathrm{pH}$ and applied voltage. (a) We depict the structures of S- and Co-terminated $\mathrm{CoS}_{2}(100)$ surfaces considered in Figure 4d. In addition, we show structures for $1 \mathrm{ML} \mathrm{O}$ adsorbed, S-terminated $\mathrm{CoS}_{2}(210)(\square)$ and for $1 \mathrm{ML} \mathrm{CoOOH} / \mathrm{CoS}_{2}(100)-\mathrm{S}_{\text {term. }}$ surface with edge-site ( $\square$ ), basal-site $(\square)$ and $2 \mathrm{ML} \mathrm{CoOOH} / \mathrm{CoS}_{2}(100)-\mathrm{S}_{\text {term. }}$ surface with edge-site $(\square)$. Red highlighted structures are the most relevant for the experiment in acidic solution. (b) Calculated ORR volcano plot of theoretical overpotentials as function of $\Delta \mathrm{G}_{\mathrm{OH}^{*}}$ for Co-O-S $+\mathrm{H}_{2} \mathrm{O}$ phases compared to existing values for Pt (111) and $\mathrm{Au}$ (111) standards. The edgereactivity of support-free $\mathrm{Co}(\mathrm{OH})_{2}(\square)$ and $\mathrm{CoOOH}(\square)$ nanostripes (NS) phases were taken from our recent work. ${ }^{33}$ All structures are also available online at catalysis-hub.org. ${ }^{36,37}$ 


\section{CONCLUSIONS}

In conclusion, we have performed detailed analysis of $\mathrm{CoS}_{2}$ catalyst for ORR performance and its structural evolution under electrochemical conditions. The intrinsic ORR activity of this system is a strong function of $\mathrm{pH}$, where much higher activities are observed for alkaline conditions than for acidic conditions. These findings hold true also for the other considered chalcogenide systems: $\operatorname{CoS}$ and $\mathrm{Ni}_{3} \mathrm{~S}_{2}$. We explain this difference by our analysis of the structural and stoichiometric changes to $\operatorname{CoS}_{2}$ surfaces. By analyzing the XPS of before and after ORR and the bulk and surface Pourbaix thermodynamics of the $\mathrm{CoS}_{2}+\mathrm{H}_{2} \mathrm{O}$ system, we discover the formation of the Co-oxide phases under alkaline conditions and applied voltage. Under acidic conditions, the XPS data and our calculated surface energetics indicate the presence of sulfur substituted by oxygen sites with increasing voltage and some dissolution of the Cometals. The predicted stable surface terminations are then used to evaluate the limiting potentials for ORR. Our DFT calculations reveal that S-site always inactive towards ORR and that Co-metal site within $\mathrm{CoS}_{2}$ surface (acidic solution) is less active than in Co-metal site within Co-oxide surface (alkaline solution). Furthermore, the electrochemical Li tuning process in organic electrolyte has been shown as an effective route to enhance the ORR activities of $\mathrm{CoS}_{2}$ in both acid and alkaline medium. While the major outcome of this method is the increase in the surface area due to formation of smaller particles, the secondary gain in the intrinsic activity can be linked to higher presence of Co-O bonds at the surface as supported by XPS data and our theoretical calculations. Recent application of $\mathrm{CoS}_{2}$ for acidic $\mathrm{ORR}^{39}$ confirms that pristine $\mathrm{CoS}_{2}$ leads to high selectivity towards $\mathrm{H}_{2} \mathrm{O}_{2}$ and reasons that $\mathrm{CoS}_{2}$ (100) lacks dual sites for effective O-O scission to produce $\mathrm{H}_{2} \mathrm{O}$. The general efficacy of this method toward T-M-X is further demonstrated by enhanced ORR activities of LiET-CoS and $\mathrm{LiET}_{-} \mathrm{Ni}_{3} \mathrm{~S}_{2}$ in alkaline and neutral medium, respectively. Above findings therefore provide critical guidelines for future design of improved ORR catalysts within the family of T-M-X. Moreover, with judiciously engineered T-M-X-based nanostructures as well as their integration with various favorable materials, this work had shown the promise for probing more advanced synergistic catalysts. 


\section{THEORETICAL SECTION}

\section{Computational Details}

The electronic structure calculations have been carried out using soft projector-augmented wave (PAW) pseudopotentials as implemented in the Vienna ab initio simulation package (VASP). We adapt the Perdew-Burke-Ernzenhof (PBE) exchange correlation functional. For a better description of Co $3 d$ electrons, value of the effective Hubbard-U parameter, $\mathrm{U}_{\mathrm{eff}}=3.32 \mathrm{eV}$ is taken from previous works on cobalt oxides. We sampled the Brillouin zone with $8 \times 8 \times 8 \Gamma$-centered Monkhorst-Pack k-point mesh per $1 \times 1 \times 1$ unit-cell of $\mathrm{CoS}_{2}$ for bulk optimization with energy cutoff of $800 \mathrm{eV}$. Optimized lattice constants of bulk $\mathrm{CoS}_{2}$ were found to be: $\mathrm{a}=\mathrm{b}=\mathrm{c}=5.60 \AA$ (exp. value is $5.538 \AA$ ) ${ }^{34,35}$ and the magnetic moment on the Co ions is $1.23 \mu \mathrm{B}$. This represents low-spin $\mathrm{Co}^{2+}$ with fully occupied $\mathrm{t}_{2 \mathrm{~g}}$ bands and singly occupied $e_{g}$ band within distorted octahedral crystal field splitting. For surface calculations, a supercell of lateral size $(2 \times 1)$ was used with $4 \times 4 \times 1$ k-point mesh per surface Co atom and energy cutoff of $400 \mathrm{eV}$. For all periodic slab calculations, we have employed symmetric slabs of 4 or more layers with vacuum of $16 \AA$ to diminish the interaction of periodic images along $\mathrm{Z}$ direction. Both clean slabs and slabs with adsorbates were always fully relaxed such that the maximum threshold force on any atom was below $0.05 \mathrm{eV} / \AA$. For each ionic configuration, the electronic energy was converged to within $10^{-4}$ $\mathrm{eV}$.

The effect of an applied voltage was modeled by applying the standard $\mathrm{CHE}^{30}$ which has been used to study a large number of metals, metal oxides/hydroxides, metal chalcogenides etc. Finally, to obtain the theoretical overpotential (eq 1) for each surface, the Gibbs free energies of the ORR intermediates were calculated at room temperature by adding the potential energy, the zero-point energy (ZPE), and the vibrational enthalpy and entropy contributions obtained by means of the harmonic approximation. We fixed the Gibb's free energy of reaction of water oxidation to the experimentally known value of $4.92 \mathrm{eV}$ to avoid well-known DFT errors in calculations of gas-phase $\mathrm{O}_{2}$. 
Binding energies of each ORR intermediates $\left(\mathrm{OOH}^{*}, \mathrm{O}^{*}\right.$ and $\left.\mathrm{OH}^{*}\right)$ were calculated relative to liquid water and hydrogen gas. The free energy of each reduction step was calculated as $\Delta \mathrm{G}=\Delta \mathrm{G}_{0}-\mathrm{eU}$, where $\Delta \mathrm{G}_{0}=\Delta \mathrm{ZPE}+\Delta \mathrm{E}-\mathrm{T} \Delta \mathrm{S}_{0}$, with $\mathrm{E}$ as the calculated DFT electronic energy, and $\mathrm{S}_{0}$ the calculated entropic contributions assuming adsorbed species have only vibrational degrees of freedom. The entropy of gas-phase species was computed under the ideal-gas limit. ZPE is the zero-point energy contribution, and $-\mathrm{eU}$ is the free energy contribution of the electron chemical potential. All contributions to $\Delta \mathrm{G}$ for all intermediates are listed in Table S3 of SI.

\section{EXPERIMENTAL SECTION}

Reagents and Apparatus. Cobalt sulfide $\left(\mathrm{CoS}_{2}, 99.98 \%\right.$ trace metals basis $)$, nickel sulfide $\left(\mathrm{Ni}_{3} \mathrm{~S}_{2}\right)$ and $5 \mathrm{wt} \%$ Nafion perfluorinated resin solution were purchased from Aldrich. Cobalt sulfide (CoS, 99.5\% metals basis) and poly(vinylidene fluoride) (PVDF) were obtained from Alfa Aesar. Characterizations were carried out using scanning electron microscopy (SEM, FEI Nova NanoSEM 450), high-resolution transmission electron microscopy (TEM, FEI Titan), X-ray photoelectron spectroscopy (XPS, SSI SProbe XPS spectrometer with Al (Ka) source), the X-ray diffractometer (XRD, PANalytical X'Pert instrument), Pine Instruments and the Biologic VMP3 multichannel system.

Electrochemical Tuning. The homogeneous slurries containing $\sim 80 \%$ active material (e.g. $\operatorname{CoS}_{2}$ ), $\sim 15 \%$ conducting carbon black, and $\sim 5 \%$ PVDF binder were first made in an ethanol solvent. Then the slurries were doctor-bladed onto copper foil and dried overnight. Next, within an argon-filled glovebox free of oxygen and water, the electrodes (copper foil with active materials) were put into pouch cells as the cathode, with polypropylene-based Celgard 2321, $1 \mathrm{M}$ solution of $\mathrm{LiPF}_{6}$ in ethylene carbonate and diethyl carbonate (EC/DEC, 1:1, from Ferro Corporation) and Li metal foil as the separator, the electrolyte and the anode, respectively. The electrochemical tuning process was performed by discharging/charging the cell to $1.0 \mathrm{~V} / 3.0 \mathrm{~V}$ vs $\mathrm{Li}+/ \mathrm{Li}$ for two cycles under a constant current of 100 $\mu \mathrm{A}$. Consequently, the tuned product was taken out, washed with water and ethanol for several times, and dried in vacuum oven for further use. 
Electrochemical Characterizations. Electrochemical testing was performed in a three-electrode system, with rotating disc as the working electrode, saturated calomel electrode (SCE) as the reference electrode, and the Carbon counter electrode, respectively, in $\mathrm{O}_{2}$ saturated $0.1 \mathrm{M} \mathrm{KOH}(\mathrm{pH}=13)$ or $0.1 \mathrm{M}$ $\mathrm{HClO}_{4}(\mathrm{pH}=1)$ solution under room temperature. The reference electrode was calibrated in $\mathrm{H}_{2}$ saturated electrolyte with respect to an in situ reverse hydrogen electrode (RHE). Then the tuned product were dispersed into $1 \mathrm{~mL}$ mixed solvent (containing $50 \mu \mathrm{L}$ of $5 \mathrm{wt} \%$ Nafion solution and $0.95 \mathrm{ml}$ ethanol) by $1 \mathrm{~h}$ of bath sonication to form an ink with a catalyst concentration of $\sim 5 \mathrm{mg} \cdot \mathrm{mL}^{-1}$. Then $8 \mu \mathrm{L}$ of the catalyst ink (containing $\sim 40 \mu \mathrm{g}$ of catalyst) was loaded onto the pre-polished glassy carbon disk (diameter of $5 \mathrm{~mm}$ ) with a loading of $\sim 0.2 \mathrm{mg} \mathrm{cm}^{-2}$. The working electrode was rotated at $1600 \mathrm{rpm}$. The disk electrode was scanned at a rate of $10 \mathrm{mV} \mathrm{s}^{-1}$ from positive to negative while the ring electrode was biased at $\sim 1.2 \mathrm{~V}$ vs. RHE. The electrode was first cycled $\sim 5$ times by cyclic voltammetry (CV) until a stable curve was achieved before measuring polarization curves. AC impedance spectroscopy (at zero overpotential) was carried out with a frequency range between 0.1 and $100 \mathrm{kHz}$ and all I-V curves have been iR-corrected. The EDLC measurements were conducted in the potential range of 1.25 to 1.30 V vs RHE, where no Faradaic reaction occurred (Figure S7).

The ORR current was determined by subtracting the $\mathrm{N}_{2}$ current from the $\mathrm{O}_{2}$ current. The potential of the ring electrode was kept at $1.2 \mathrm{~V}$ (vs. RHE) for the detection of $\mathrm{H}_{2} \mathrm{O}_{2}$ produced on the disk electrode and the selectivity for the two-electron reduction, was calculated using the following equation. Taking into account that the total disk current $\left(\mathrm{I}_{D}\right)$ is the sum of the $\mathrm{O}_{2}$ reduction currents to water $\left(\mathrm{I}_{\mathrm{H}_{2} \mathrm{O}}\right)$, and to $\mathrm{H}_{2} \mathrm{O}_{2}\left(\mathrm{I}_{\mathrm{H}_{2} \mathrm{O}_{2}}\right): \mathrm{I}_{\mathrm{D}}=\mathrm{I}_{\mathrm{H}_{2} \mathrm{O}}+\mathrm{I}_{\mathrm{H}_{2} \mathrm{O}_{2}}$, and using the ring currents $\left(\mathrm{I}_{\mathrm{R}}\right)$ and the collection efficiency $N$ of the ring currents: $\mathrm{I}_{\mathrm{H}_{2} \mathrm{O}_{2}}=\mathrm{I}_{\mathrm{R}} \mathrm{N}^{-1}$, the selectivity for $\mathrm{H}_{2} \mathrm{O}_{2}$ formation $\left(\mathrm{H}_{2} \mathrm{O}_{2} \%\right)$ could be calculated from the ratio between $\mathrm{O}_{2}$ consumption rate toward $\mathrm{H}_{2} \mathrm{O}_{2}\left(\mathrm{n}_{\mathrm{O}_{2}(2 \mathrm{e}-)}=\mathrm{I}_{\mathrm{H}_{2} \mathrm{O}_{2}} / 2 \mathrm{~F}\right)$ and total consumption rate $\left(\mathrm{n}_{\mathrm{O}_{2}}=\mathrm{I}_{\mathrm{H}_{2}} \mathrm{O}_{2} / 2 \mathrm{~F}+\mathrm{I}_{\mathrm{H}_{2}} \mathrm{O}_{\mathrm{H}_{2} \mathrm{O}} / 4 \mathrm{~F}\right)^{38}$

$$
\mathrm{H}_{2} \mathrm{O}_{2} \%=200 \times \frac{\mathrm{I}_{\mathrm{R}} / \mathrm{N}}{\mathrm{I}_{\mathrm{D}}+\mathrm{I}_{\mathrm{R}} / \mathrm{N}}
$$


where the collection efficiency $(\mathrm{N})$ can be determined from the measurement of hexacyanoferrate (III) reduction.

\section{ASSOCIATED CONTENT \\ Supporting Information}

The Supporting Information is available free of charge on the ACS Publications website at DOI:xxx.

Galvanostatic cycling profile of $\mathrm{CoS}$ and $\mathrm{Ni}_{3} \mathrm{~S}_{2}$, Characterizations of C-CoS and LiET-CoS, Characterizations of C-Ni $\mathrm{S}_{2}$ and LiET-Ni $\mathrm{S}_{2}$, Normalized RRDE curves of C-CoS $\mathrm{C}_{2}$ and LiET-CoS 2 , Observed XPS changes after ORR of LiET-CoS 2 , Pourbaix diagram of bulk phases Co-O-S $+\mathrm{H}_{2} \mathrm{O}$ system without any surface stabilization, Surface Pourbaix diagram representing clean $1 \mathrm{ML} \mathrm{CoOOH}$ NS-edge/CoS 2 , Surface Pourbaix diagram representing clean $2 \mathrm{ML} \mathrm{CoOOH}$ NS-edge/CoS 2 , Calculated scaling of $\mathrm{OOH}^{*}$ and $\mathrm{O}^{*}$ free energies relative to $\mathrm{OH}^{*}$ free energies, Experimental Gibbs free energies of bulk Co-O-S systems used to construct the bulk Pourbaix diagrams, Gibbs Free adsorption energies of ORR intermediates on different $\mathrm{CoS}_{2}$ surfaces, Gibbs free energies corrections for the adsorbates in the gas phase and on the surface.

\section{ASSOCIATED CONTENT}

\section{Corresponding Authors}

*zww@nju.edu.cn or zww@stanford.edu

*bajdich@slac.stanford.edu

*yicui@stanford.edu

\section{ORCID}

\section{Notes}

The authors declare no competing financial interest.

\section{ACKNOWLEDGMENT}

This work was performed work under the funding from Toyota Research Institute. W.Z. would like to acknowledge support from the National Natural Science Foundation of China (Grant 21675080), the Natural Science Foundation of Jiangsu Province (Grant BK 20170073). We also acknowledge the use of the computer time allocation at the National Energy Research Scientific Computing Center, a DOE Office of Science User Facility supported by the Office of Science of the U.S. Department of Energy under Contract No. DE-AC02-05CH11231.

\section{REFERENCES}


(1) Shao, M.; Chang, Q.; Dodelet, J. P.; Chenitz, R. Recent Advances in Electrocatalysts for Oxygen Reduction Reaction. Chem. Rev. 2016, 116, 3594-3657.

(2) Dai, L.; Xue, Y.; Qu, L.; Choi, H. J.; Baek, J. B. Metal-Free Catalysts for Oxygen Reduction Reaction. Chem. Rev. 2015, 115, 4823-4892.

(3) Wu, J.; Yang, H. Platinum-Based Oxygen Reduction Electrocatalysts. Accounts Chem. Res. 2013, $46,1848-1857$.

(4) Nie, Y.; Li, L.; Wei, Zidong. Recent advancements in Pt and Pt-free catalysts for oxygen reduction reaction. Chem. Soc. Rev. 2015, 44, 2168-2201.

(5) Wu, G.; Zelenay, P. Nanostructured Nonprecious Metal Catalysts for Oxygen Reduction Reaction. Accounts Chem. Res. 2013, 46, 1878-1889.

(6) Wu G, More KL, Johnston CM, Zelenay P High-performance electrocatalysts for oxygen reduction derived from polyaniline, iron, and cobalt. Science 2011, 332, 443-447.

(7) Yang, L.; Cheng, D.; Xu, H.; Zeng, X.; Wan, X.; Shui, J.; Xiang, Z.; Cao, D. Unveiling the high activity origin of single atom iron catalysts for Oxygen Reduction Reaction. Proc. Natl Acad. Sci. USA 2018, 115(26), 6626-6631.

(8) Xu HX, Cheng DJ, Cao DP, Zeng XC A universal principle for a rational design of single-atom electrocatalysts, Nat. Catal. 2018, 1, 339-348.

(9) Behret, H.; Binder, H.; Sandstede, G. Electrocatalytic Oxygen Reduction with Thiospinels and Other Sulphides of Transition Metals. Electrochim. Acta 1975, 20, 111-117.

(10) Wang, H.; Liang, Y.; Li, Y.; Dai, H. $\mathrm{Co}_{1-\mathrm{x}} \mathrm{S}-$ Graphene Hybrid: A High-Performance Metal Chalcogenide Electrocatalyst for Oxygen Reduction. Angew. Chem. Int. Ed. 2011, 50, 10969-10972.

(11) Ganesan, P.; Prabu, M.; Sanetuntikul, J.; Shanmugam, S. Cobalt Sulfide Nanoparticles Grown on Nitrogen and Sulfur Codoped Graphene Oxide: An Efficient Electrocatalyst for Oxygen Reduction and Evolution Reactions. ACS Catal. 2015, 5, 3625-3637.

(12) Lee, M.; Oh, H-S.; Cho, M. K.; Ahn, J-P.; Hwang, Y. J.; Min, B. K. Activation of a Ni Electrocatalyst through Spontaneous Transformation of Nickel Sulfide to Nickel Hydroxide in An Oxygen Evolution Reaction. Appl. Catal. B-Environ. 2018, 233, 130-135.

(13) Liu, T.; Liu, Q.; Asiri, A. M.; Luo, Y.; Sun, X. An Amorphous CoSe Film Behaves as an Active and Stable Full Water-Splitting Electrocatalyst under Strongly Alkaline Conditions. Chem. Commun. 2015, 51, 16683-16686.

(14) Ryu, J.; Jung, N.; Hyun Jang, J. H.; Kim, H.-J.; Yoo, S. J. In Situ Transformation of HydrogenEvolving CoP Nanoparticles: Toward Efficient Oxygen Evolution Catalysts Bearing Dispersed Morphologies with Co-oxo/hydroxo Molecular Units. ACS Catal. 2015, 5, 4066-4074.

(15) Abroshan, H.; Bothra, P.; Back, S.; Kulkarni, A.; Nørskov, J. K.; Siahrostami, S. Ultrathin Cobalt Oxide Overlayer Promotes Catalytic Activity of Cobalt Nitride for the Oxygen Reduction Reaction. $J$. Phys. Chem. C 2018, 122, 4783-4791.

(16) Yan, B.; Krishnamurthy, D.; Hendon, C. H.; Deshpande, S.; Surendranath, Y.; Viswanathan, V. Surface Restructuring of Nickel Sulfide Generates Optimally Coordinated Active Sites for Oxygen Reduction Catalysis. Joule 2017, 1, 600-612. 
(17) Du, C.; Li, P.; Yang, F.; Cheng, G.; Chen, S.; Luo, W. Monodisperse Palladium Sulfide as Efficient Electrocatalyst for Oxygen Reduction Reaction. ACS Appl. Mater. Interfaces 2018, 10, 753-761.

(18) Wang, H.; Lu, Z.; Xu, S.; Kong, D.; Cha, J. J. Zheng, G.; Hsu, P-C.; Yan, K.; Bradshaw, D.; Prinz, F. B.; Cui, Y. Electrochemical Tuning of Vertically Aligned $\mathrm{MoS}_{2}$ Nanofilms and Its Application in Improving Hydrogen Evolution Reaction. Proc. Natl. Acad. Sci. USA 2013, 110, 19701-19706.

(19) Lu, Z.; Wang, H.; Kong, D.; Yan, K.; Hsu, P-C.; Zheng, G.; Yao, H.; Liang, Z.; Sun, X.; Cui, Y. Electrochemical Tuning of Layered Lithium Transition Metal Oxides for Improvement of Oxygen Evolution Reaction. Nat. Commun. 2014, 5, 4345.

(20) Wang, H.; Lee, H-W.; Deng, Y.; Lu, Z.; Hsu, P-C.; Liu, Y.; Lin, D.; Cui, Y. Bifunctional Nonnoble Metal Oxide Nanoparticle Electrocatalysts through Lithium-induced Conversion for Overall Water Splitting. Nat. Commun. 2015, 6, 7261.

(21) Liu, Y.; Wang, H.; Lin, D.; Liu, C.; Hsu, P-C.; Liu, W.; Chen, W.; Cui, Y. Electrochemical Tuning of Olivine-Type Lithium Transition-metal Phosphates as Efficient Water Oxidation Catalysts. Energy Environ. Sci. 2015, 8, 1719-1724.

(22) Lu, Z.; Chen, G.; Li, Y.; Wang, H.; Xie, J.; Liao, L.; Liu, C.; Liu, Y.; Wu, T.; Li, Y.; Luntz, A. C.; Bajdich, M.; Cui, Y. Identifying the Active Surfaces of Electrochemically Tuned $\mathrm{LiCoO}_{2}$ for Oxygen Evolution Reaction. J. Am. Chem. Soc. 2017, 139, 6270-6276.

(23) Wang, H.; Xu, S.; Tsai, C.; Li, Y.; Liu, C.; Zhao, J.; Liu, Y.; Yuan, H.; Abild-Pedersen, F.; Prinz, F. B.; Nørskov, J. K.; Cui, Y. Direct and Continuous Strain Control of Catalysts with Tunable Battery Electrode Materials. Science, 2016, 354, 1031-1036.

(24) Poizot, P.; Laruelle, S.; Grugeon, S.; Tarascon, J.-M. Rationalization of the Low-Potential Reactivity of 3d-Metal-Based Inorganic Compounds toward Li. J. Electrochem. Soc. 2002, 149, A1212A1217.

(25) Yan, J. M.; Huang, H. Z.; Zhang, J.; Liu, Z. J.; Yang, Y. A Study of Novel Anode Material CoS 2 for Lithium Ion Battery. J. Power Sources 2005, 146, 264-269.

(26) https://materialsproject.org/materials/mp-757100/

(27) Protopopoff, E.; Marcus, P. Potential-pH Diagram for Sulfur and Hydroxyl Adsorbed on Silver in Water Containing Sulfides. Electrochim. Acta 2012, 63, 22-27.

(28) Ardizzone, S.; Trasatti, S. Interfacial Properties of Oxides with Technological Impact in Electrochemistry. Adv. Colloid Interface Sci. 1996, 64, 173-251.

(29) Barin, I. Thermochemical Data of Pure Substances. 3 ${ }^{\text {rd }}$ ed.; Weinheim; New York: VCH, 1995.

(30) Nørskov, J. K.; Rossmeisl, J.; Logadottir, A.; Lindqvist, L.; Kitchin, J. R.; Bligaard, T.; Jonsson, H. Origin of the Overpotential for Oxygen Reduction at a Fuel-Cell Cathode. J. Phys. Chem. B 2004, $108,17886-17892$.

(31) Kulkarni, A.; Siahrostami, S.; Patel, A.; Nørskov, J. K. Understanding Catalytic Activity Trends in the Oxygen Reduction Reaction. Chem. Rev. 2018, 118, 2302-2312

(32) Viswanathan, V.; Hansen, H. A.; Rossmeisl, J.; Nørskov, J. K. Universality in Oxygen Reduction Electrocatalysis on Metal Surfaces. ACS Catal. 2012, 2, 1654-1660. 
(33) Zhao, Z.; Schlexer Lamoureux, P.; Kulkarni, A.; Bajdich, M. Trends in Oxygen Electrocatalysis of 3d-Layered (Oxy)(Hydro)Oxides. ChemCatChem 2019, 11, 3423-3431.

(34) Nowack, E.; Schwarzenbach, D.; Gonschorek, W.; Hahn, T. Deformationsdichten in $\mathrm{CoS}_{2}$ und Ni $\mathrm{S}_{2}$ mit Pyritstruktur. Z. Kristallogr. 1989, 186, 213-215

(35) Nowack, E.; Schwarzenbach, D.; Hahn, T. Charge Densities in $\mathrm{CoS}_{2}$ and $\mathrm{NiS}_{2}$ (Pyrite Structure). Acta Crystallogr. B 1991, 47, 650-659.

(36) Winther, K. T.; Hoffmann, M. J.; Boes, J. R.; Mamun, O.; Bajdich, M.; Bligaard, T. CatalysisHub.Org, an Open Electronic Structure Database for Surface Reactions. Sci. Data 2019, 6, 75.

(37) Computational Data: https://www.catalysis-hub.org/publications/ZhaoImproved2019.

(38) Jiang, Y.; Ni, P.; Chen, C. Lu, Y.; Yang, P.; Kong, B. Fisher, A.; Wang, X.; Adv. Energy Mater. 2018, 8, 1801909.

(39) Sheng, H.; Hermes, E. D.; Yang, X.; Ying, D.; Janes, A. N.; Li, W.; Schmidt, J. R.; Jin, S. Electrocatalytic Production of $\mathrm{H}_{2} \mathrm{O}_{2}$ by Selective Oxygen Reduction Using Earth-Abundant Cobalt Pyrite $\left(\mathrm{CoS}_{2}\right)$. ACS Catal. 2019, 9 (9), 8433-8442.

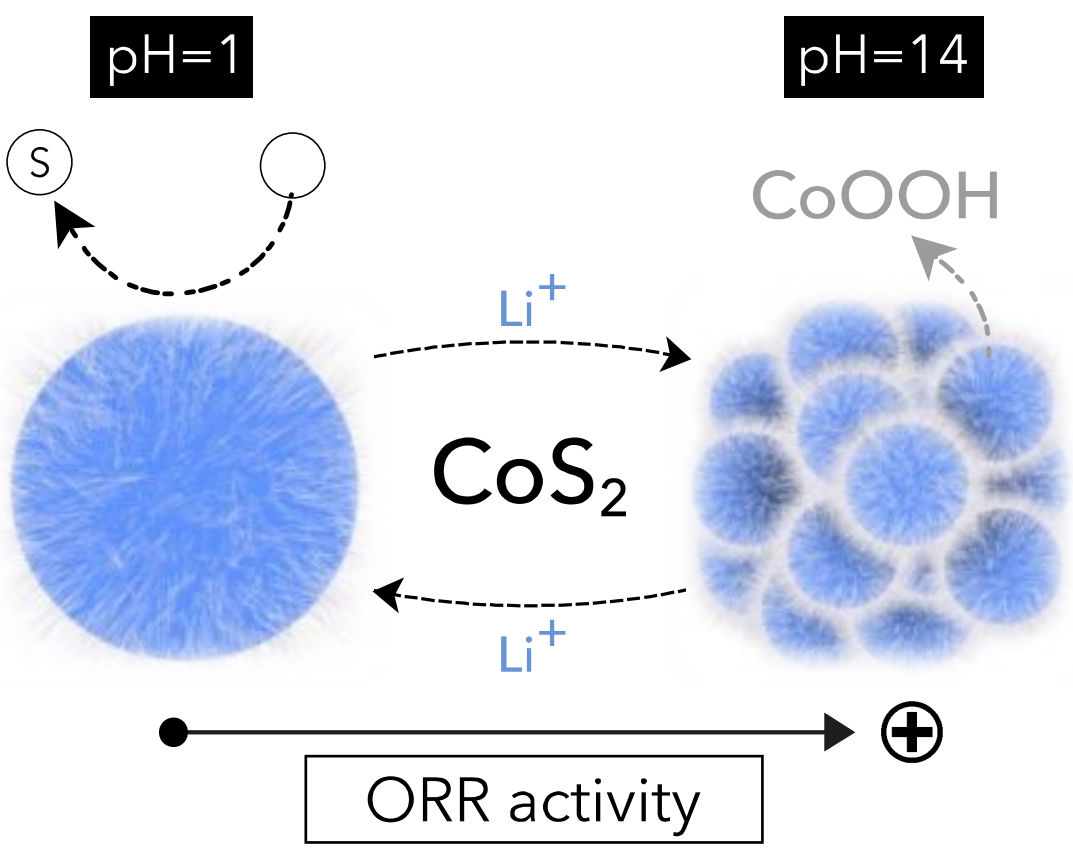

TOC Figure: 


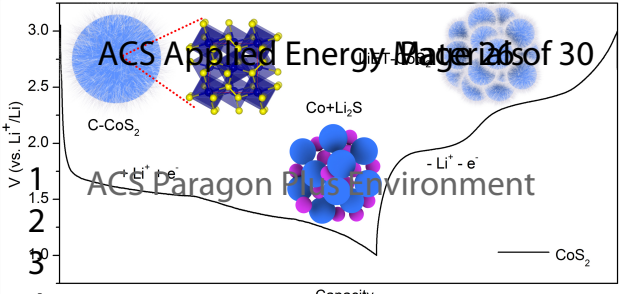


a

Page 27 of 30 ACS Applied Energy

$$
\begin{aligned}
& 1 \\
& 2 \\
& 3 \\
& 4 \\
& 5 \\
& 6 \\
& 7 \\
& 8 \\
& 9
\end{aligned}
$$

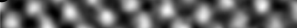

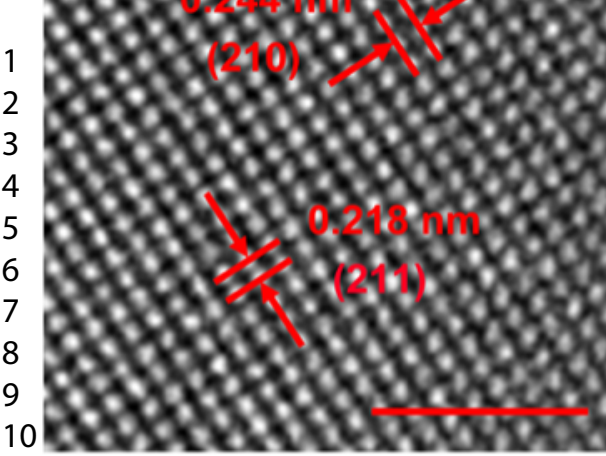

$c_{1}^{1}$

13

14

15

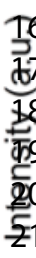

22

23

24

25

26

27

Materials

A.
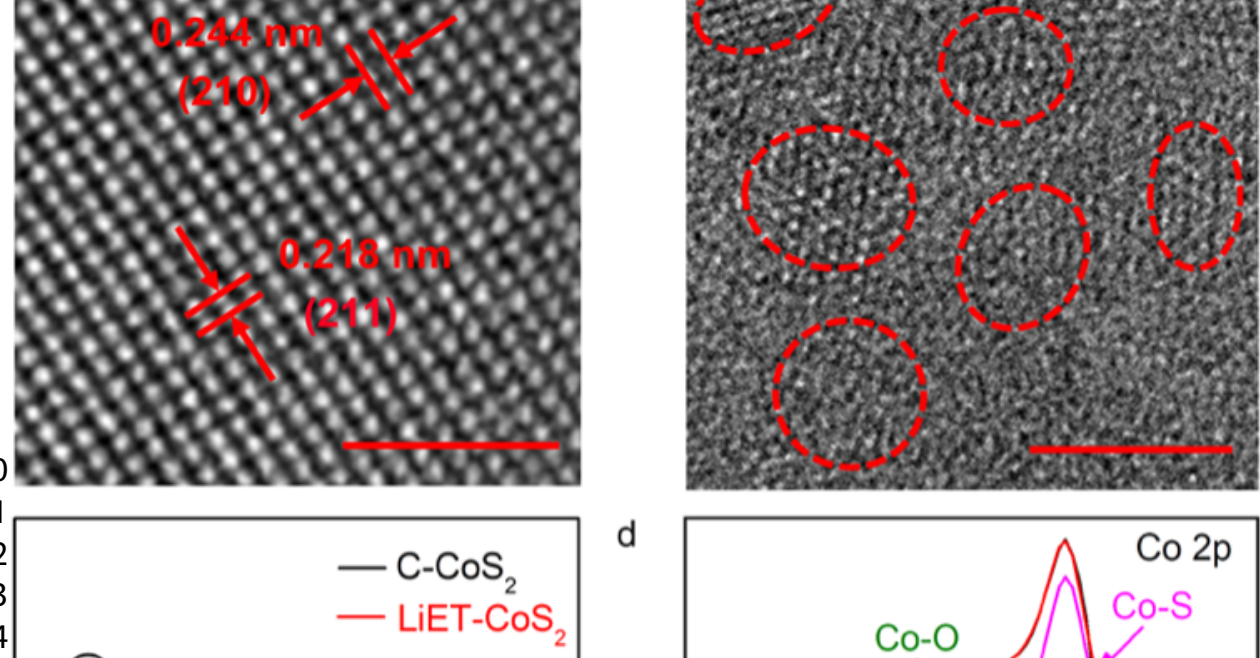

5

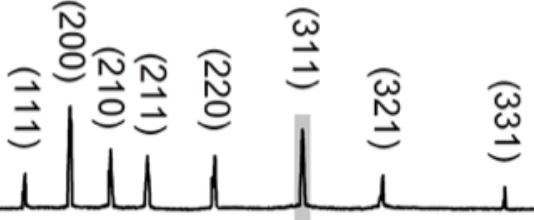

-

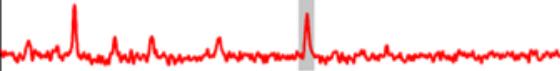

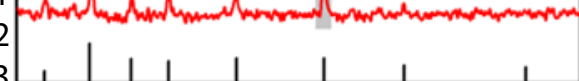

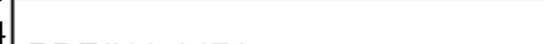

PDF\#41-1471

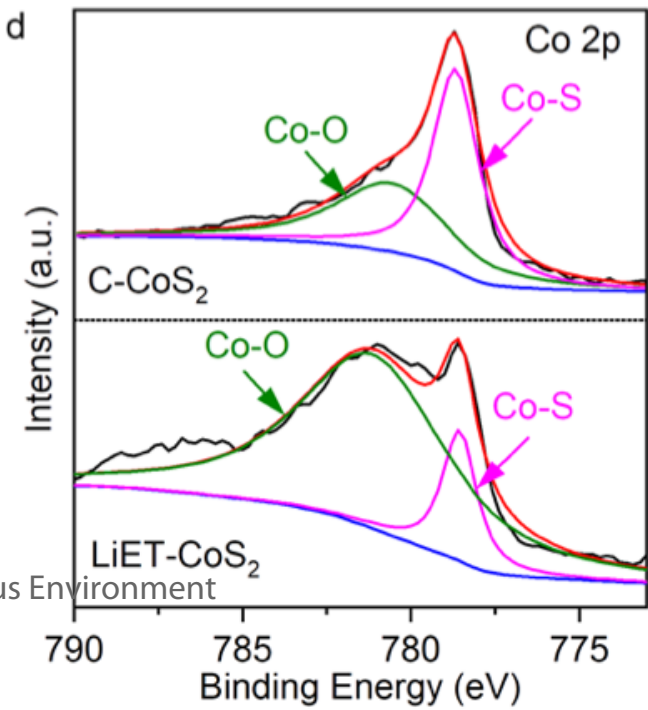




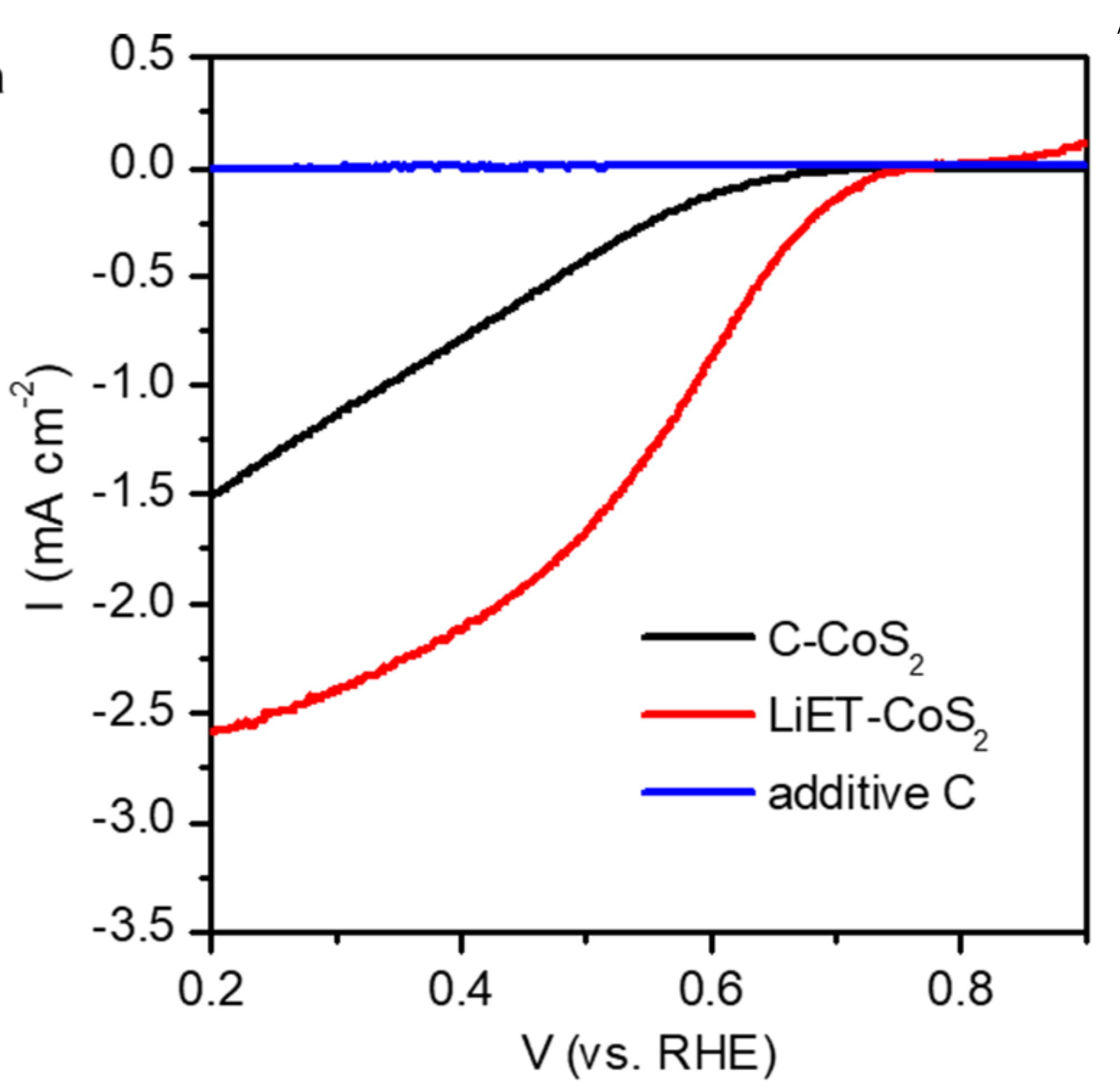

ACS Applied Energy Materia

Page 28 of 30

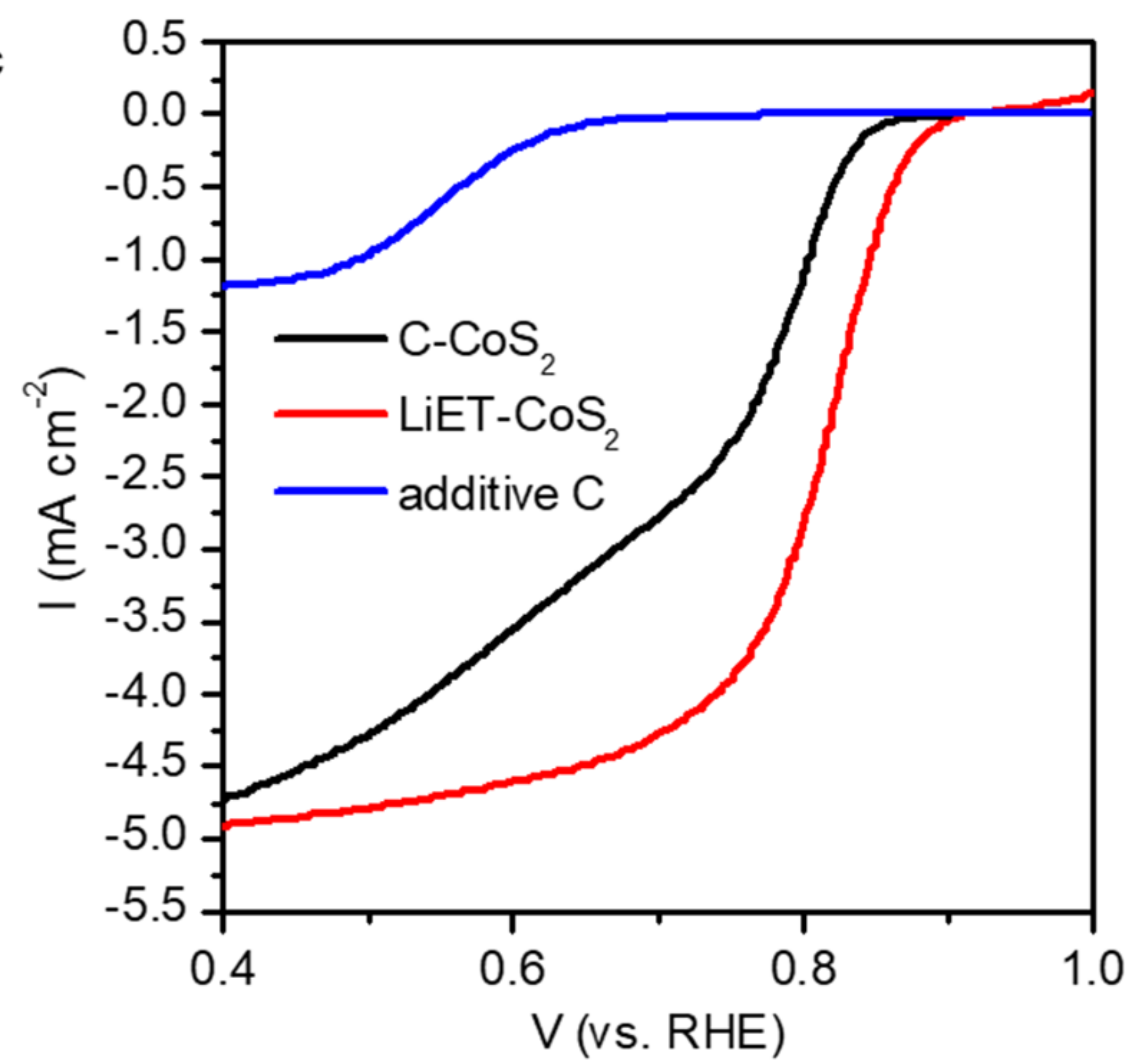

d
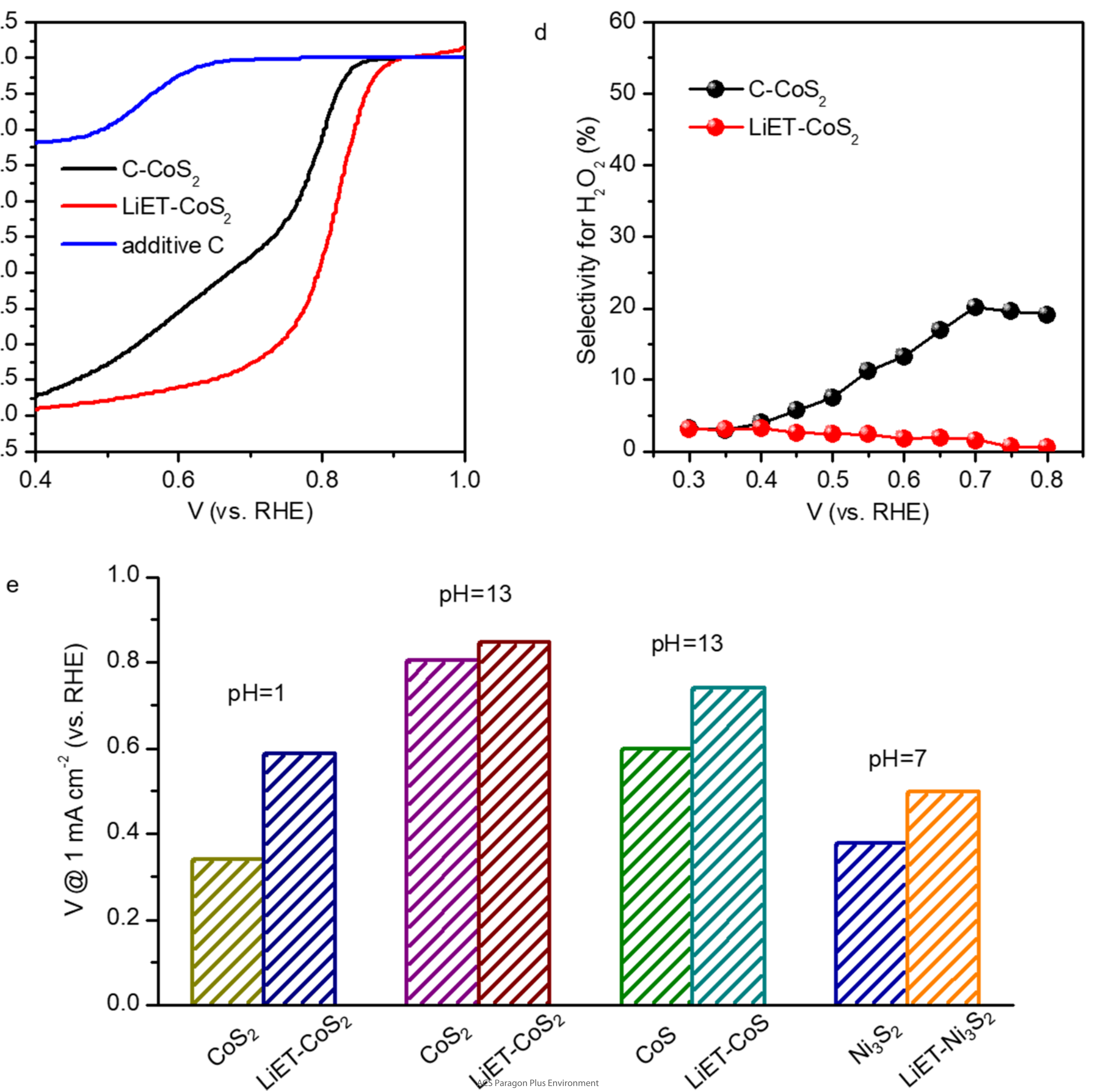


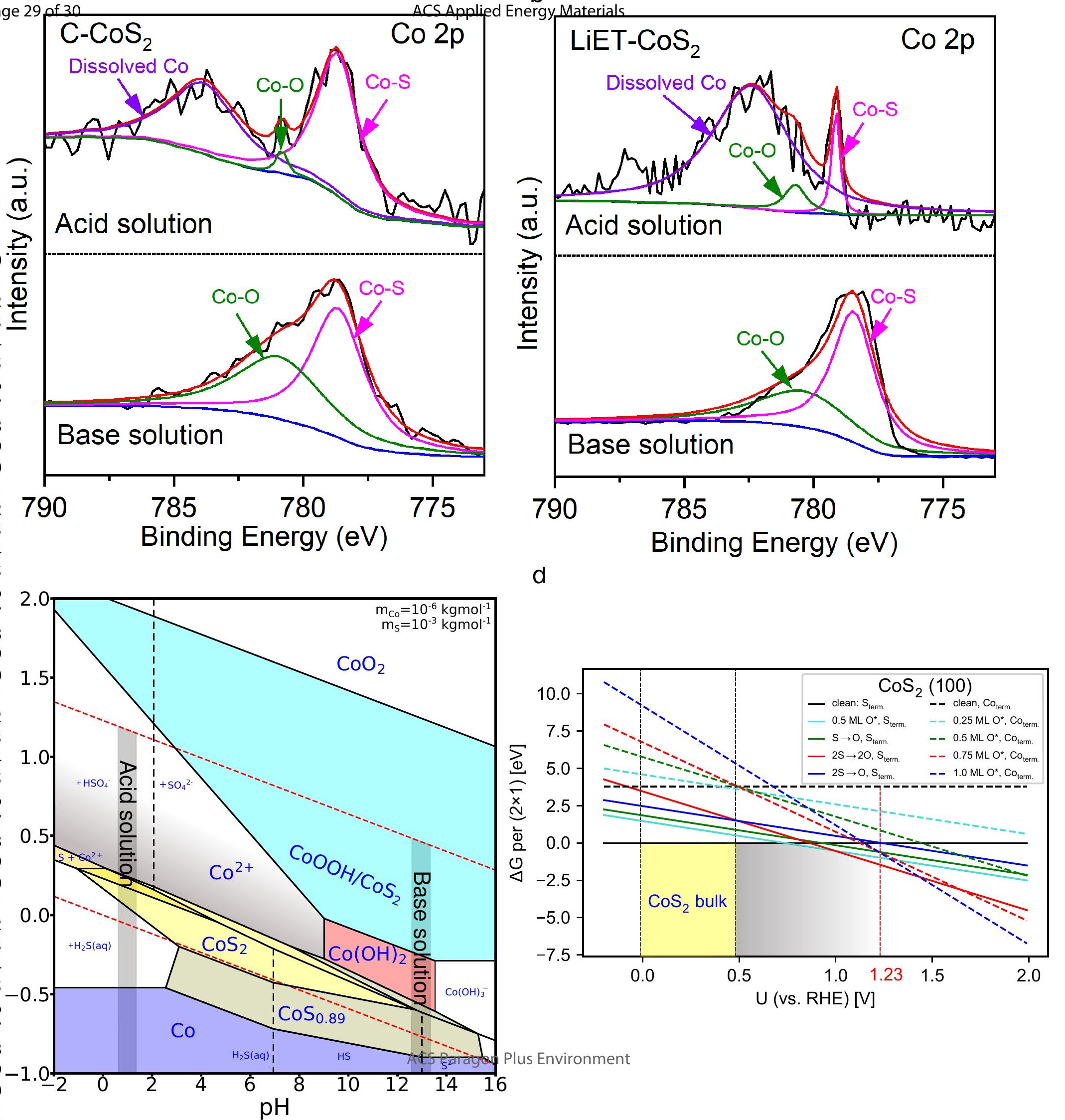


